NBER WORKING PAPER SERIES

ETHNIC COMPLEMENTARITIES AFTER THE OPENING OF CHINA:

HOW CHINESE GRADUATE STUDENTS AFFECTED THE PRODUCTIVITY OF THEIR ADVISORS

\author{
George J. Borjas \\ Kirk B. Doran \\ Ying Shen \\ Working Paper 21096 \\ http://www.nber.org/papers/w21096 \\ NATIONAL BUREAU OF ECONOMIC RESEARCH \\ 1050 Massachusetts Avenue \\ Cambridge, MA 02138 \\ April 2015
}

The views expressed herein are those of the authors and do not necessarily reflect the views of the National Bureau of Economic Research.

NBER working papers are circulated for discussion and comment purposes. They have not been peerreviewed or been subject to the review by the NBER Board of Directors that accompanies official NBER publications.

(C) 2015 by George J. Borjas, Kirk B. Doran, and Ying Shen. All rights reserved. Short sections of text, not to exceed two paragraphs, may be quoted without explicit permission provided that full credit, including $(\odot$ notice, is given to the source. 
Ethnic Complementarities after the Opening of China: How Chinese Graduate Students Affected the Productivity of Their Advisors

George J. Borjas, Kirk B. Doran, and Ying Shen

NBER Working Paper No. 21096

April 2015

JEL No. D83,J24,J61,O31

\begin{abstract}
The largest and most important flow of scientific talent in the world is the migration of international students to the doctoral programs offered by universities in industrialized countries. This paper uses the opening of China in 1978 to estimate the causal effect of this flow on the productivity of their professors in mathematics departments across the United States. Our identification strategy relies on both the suddenness of the opening of China and on a key feature of scientific production: intra-ethnic collaboration. The new Chinese students were more likely to be mentored by American professors with Chinese heritage. The increased access that the Chinese-American advisors had to a new pool of considerable talent led to a substantial increase in their productivity. Despite these sizable intra-ethnic knowledge spillovers, the relatively fixed size of doctoral mathematics programs (and the resulting crowdout of American students) implied that comparable non-Chinese advisors experienced a decline in the number of students they mentored and a concurrent decline in their research productivity. In fact, the productivity gains accruing to Chinese-American advisors were almost exactly offset by the losses suffered by the non-Chinese advisors. Finally, it is unlikely that the gains from the supply shock will be more evident in the next generation, as the Chinese students begin to contribute to mathematical knowledge. The rate of publication and the quality of the output of the Chinese students is comparable to that of the American students in their cohort.
\end{abstract}

George J. Borjas

Harvard Kennedy School

79 JFK Street

Cambridge, MA 02138

and NBER

gborjas@ harvard.edu

Kirk B. Doran

438 Flanner Hall

University of Notre Dame

Notre Dame, IN 46556

kdoran@nd.edu
Ying Shen

Department of Economics

University of Notre Dame

Notre Dame, IN 46556

Ying.Shen.24@nd.edu 


\title{
Ethnic Complementarities after the Opening of China: How Chinese Graduate Students Affected the Productivity of Their Advisors
}

\author{
George J. Borjas, Kirk B. Doran, and Ying Shen*
}

\section{Introduction}

Scientific knowledge is essential for long-term economic growth. Because science is a social and reciprocal endeavor (Lucas, 2009), the production of scientific knowledge depends heavily on knowledge spillovers in which one person's knowledge output becomes another person's knowledge input. Although a number of studies have found evidence for such spillovers (e.g., Waldinger, Moser, and Voena, 2014), the overall evidence is mixed. Moreover, even when spillovers are found, little is known about how to harness them. Despite this uncertainty, one specific proposal surfaces repeatedly in policy discussions: the large-scale immigration of high-skill persons opens up the opportunity for knowledge spillovers to occur and for increasing the productivity of the native-born scientific workforce.

A careful examination of the existing research reveals an interesting pattern. On the one hand, there seem to be powerful knowledge spillovers among scientists who are directly collaborating with each other (Waldinger, 2010; Azoulay, Zivin, and Wang, 2010). On the other hand, diminishing returns may dominate when scientists compete for topicspecific or location-specific resources (Borjas and Doran, 2012; and the related work of Waldinger, 2012). A natural inference that can be drawn from these conflicting results is that a high-skill supply shock is more likely to generate spillovers that outweigh the competitive effects if: (a) collaboration with the newcomers is more likely; and/or (b) the newcomers are less likely to compete for the scarce resources that are necessary for knowledge production, such as faculty slots, grant resources, and journal space.

In this paper, we examine the resulting productivity effects of a large high-skill supply shock that shares both of these characteristics: the "immigration" of young graduate students in mathematics from China. These students were eager to learn from and Dame.

\footnotetext{
* Borjas: Harvard Kennedy School; Doran and Shen, Department of Economics, University of Notre
} 
collaborate with professors in the United States, but, as graduate students, were not competing for funds or job positions with their advisors. Put differently, there was no direct competition between the Chinese graduate students and their advisors.

Our study makes use of a historic natural experiment that affected the supply of Chinese doctoral students: Vice Premier Deng Xiaoping's "Open Up" reforms of December 1978. Before Deng Xiaoping's rapid rise to power, the Cultural Revolution both destroyed the Chinese higher education system and engendered strict isolationism, causing China to send virtually no students to doctoral programs abroad for over a decade. After 1978, Deng Xiaoping's reforms both facilitated the acquiring of the secondary education that is a prerequisite to "produce" future graduate students, and encouraged the students to acquire their graduate training in Western universities. This policy shift resulted in a very large and sudden increase in the number of Chinese students sent to study in doctoral programs abroad.

The influx of Chinese graduate students in the doctoral mathematics programs of American universities can be expected to have many productivity repercussions. One particular consequence of this supply shock is implied by the extensive literature on diasporas. Multiple studies have documented that people of similar ethnic background dispersed around the world are much more likely to communicate with each other, to spread technological knowledge within their ethnic and linguistic network, and to collaborate on joint ventures (Rauch and Trindade, 2002; Nanda and Khana, 2010; Kerr, 2008; and Kerr and Kerr, 2014). The "ethnic magnet" hypothesis suggests that scientists may experience the most powerful knowledge spillovers when they interact with those most ethnically similar to them. In fact, as Freeman and Huang (2014) show, there is a very strong propensity for ethnically similar scientists to coauthor scientific papers.

If scientists indeed experience the most powerful knowledge spillovers when they interact with those most ethnically similar to them, the supply shock of Chinese graduate students in mathematics should result in three distinct outcomes. First, advisors with Chinese ancestry should mentor more of the new Chinese doctoral students than would otherwise similar "American" advisors (i.e., mathematicians who did not have Chinese ancestry). Second, Chinese-American advisors should coauthor with their new Chinese students more frequently than would be predicted by their earlier collaboration profiles, or 
than otherwise similar American advisors are doing with the (smaller number of) Chinese students that they managed to attract. Third, the increased intra-ethnic collaboration between Chinese-American advisors and Chinese graduate students should perhaps lead to greater research output for those advisors, even apart from coauthoring with the Chinese students, as the knowledge gained from the new interactions becomes an input in their own knowledge production function.

In order to test these implications, we make use of two datasets introduced in Borjas and Doran (2012). The first is the archive maintained by the American Mathematical Society (AMS) MathSciNet database of all papers published in mathematics and related fields worldwide. The second is a collection of advisor-advisee matches created and maintained by the Mathematics Genealogy Project (MGP). Using name-matching techniques, we identify which American advisors and which doctoral students in the MGP data likely had Chinese ancestry. We then match records from the AMS and MGP files to examine the trend in the scientific output of advisors over time.

Employing a simple difference-in-differences strategy, we find that the productivity of American advisors with Chinese ancestry increased substantially after the opening up of China and the influx of Chinese students began to substantially affect enrollment in American mathematics departments. Specifically, the Chinese-American advisors began to mentor more Chinese students; these mentoring relationships resulted in an increased number of published papers, some of which were the result of collaborations with the Chinese students; and there was some increased productivity for the Chinese-American advisors even after netting out the "direct" effect of increased collaboration with Chinese graduate students.

Although these beneficial productivity effects are the ones that are commonly conjectured and emphasized in the literature, our data allows us to carry the exercise one step further, a step that has not been examined by previous studies. In particular, the supply shock could also influence the productivity of the American advisors who did not have Chinese ancestry. After all, the increased mentoring opportunities for the ChineseAmerican advisors may have led to a shift in departmental resources, and these resources likely flowed away from the pre-existing American advisors to the pre-existing ChineseAmerican advisors. This kind of redistribution would be particularly important if there are 
significant crowdout effects from the supply shock-in other words, if American graduate students were displaced by the increased number of Chinese students because of the relatively fixed size of mathematics doctoral programs. In short, although there was no direct competition between the Chinese graduate students and their advisors, the supply shock may have introduced indirect competitive forces between the Chinese-American advisors and the American advisors who did not have a Chinese heritage.

Our empirical analysis contrasts the experience of the Chinese-American advisors with that of two distinct groups of American mathematicians: the advisors employed in the departments that attracted most of the Chinese students and the advisors employed in departments that attracted few Chinese students. It turns out that the departments that attracted the Chinese students were departments that had a Chinese "connection," as measured by the presence of at least one Chinese-American professor actively advising students prior to the opening of China.

Not surprisingly, the supply shock had differential effects on the various groups of advisors. Specifically, there was a drop in the productivity of the American advisors employed in the mathematics departments most affected by the supply shock. These advisors experienced a decline in the number of students they mentored and in the number of papers they published. As is typical with supply shocks, therefore, there are winners and losers. In particular, our study documents that there are winners and losers even when there are sizable productivity spillovers benefitting a particular segment of the scientific workforce.

Our data allows us to add up the productivity gains accruing to the winners and the productivity losses suffered by the losers to calculate the change in the aggregate output of the pre-existing advisors. The exercise reveals an unambiguous conclusion: the aggregate output did not change. The additional research output produced by the pre-existing Chinese-American advisors was almost exactly offset by the smaller output produced by the affected American advisors. Moreover, there is no evidence that the aggregate output is somehow "better" in any qualitative sense.

Finally, our analysis examines the possibility that the efficiency gains from the supply shock might show up in subsequent years, as the Chinese students become part of the mathematics profession and their research output contributes to the body of 
mathematical knowledge. There is, however, no evidence to suggest that the quantity or quality of the output eventually produced by the Chinese students themselves is far superior to that produced by the comparable American students from their cohort. ${ }^{1}$

In sum, substantial knowledge spillovers were indeed generated by a supply shock of doctoral students who had strong incentives to collaborate with their ethnically similar advisors. As is often the case, however, such supply shocks have additional ramifications, particularly on the pre-existing workers who are not part of the ethnic network. These additional ramifications can greatly attenuate the net benefits resulting from the knowledge spillovers.

\section{Historical Background}

Between 1949 and 1969, the Chinese communist regime was firmly committed to the Sino-Soviet alliance. As part of this alliance, the Chinese government implemented the "leaning to one side" policy, a policy that committed the People's Republic of China to pursue actions that systematically favored interactions with the communist bloc. In the higher education context, this policy instituted strict controls on the subset of countries that Chinese students were allowed to study in, with the Soviet Union becoming the dominant country receiving Chinese international students (He, 2008). Between 1949 and 1965, for example, 8,424 Chinese students, or about 78 percent of all international students originating in China, enrolled in Soviet universities, and most of these students enrolled in science and technology programs. Not surprisingly, the United States received a trivially small number of Chinese students during the period-only around 200 Chinese students enrolled in the universities of Western developed countries. Moreover, most of the 200 Chinese students in Western countries studied foreign languages, with only 21 of them enrolling in programs in the natural sciences (Mathur, 2007).

The social, economic, and political upheaval that began in the spring of 1966, which is now collectively known as the Cultural Revolution, and which lasted until October 1976,

\footnotetext{
${ }^{1}$ In related work, Stuen, Mobarak, and Maskus (2012) find that exogenous increases in the total number of graduate students enrolled in a given field at a given university in a given year cause an increase in the total number of publications produced (by professors and students combined), although the impact of an additional foreign or domestic graduate students seems, on average, to be the same.
} 
further cemented the geographic and intellectual isolation of Chinese students. The higher education system in China was effectively destroyed during those years so that a remarkably high number of young people lost their opportunities to ever pursue a higher education (Deng, 1997). Premier Mao Zedong himself laid out the parameters for how the Cultural Revolution would be applied in the education sector by advising students to: ${ }^{2}$

Hold high the great banner of the proletarian cultural revolution, thoroughly expose the reactionary bourgeois stand of those so-called "academic authorities" who oppose the Party and socialism, thoroughly criticize and repudiate the reactionary bourgeois ideas in the sphere of academic work, education, journalism, literature and art and publishing, and seize the leadership in these cultural spheres.

Not surprisingly, the urgent call to action had dramatic and violent consequences. As MacFarquhar and Schoenhals (2006, p. 126) describe in their comprehensive history of the Cultural Revolution: ${ }^{3}$

In Beijing's western district alone, in the course of little more than two weeks, the violence left close to one hundred teachers, school officials, and educational cadres dead. The number of those injured was, according to one investigation, simply "too large to be calculated". In every one of eighty-five elite colleges, middle schools, and elementary schools throughout China investigated by a Chinese scholar after the Cultural Revolution, teachers were tortured by students. At twelve of them, a teacher was beaten to death; at one school, two teachers were murdered.

As part of the ideological cleansing, China further implemented a closed-door policy that led to a self-imposed international isolation, both from countries in the communist alliance and from Western countries. This closed-door policy effectively shut down the opportunity for any Chinese student to study abroad. Not surprisingly, the combination of the violent persecution of educators, the political upheaval in educational institutions, and the closed-door policy substantially shrank the domain of the knowledge production

\footnotetext{
2 Circular of the Central Committee of the Chinese Communist Party, May 16, 1966. See https://www.marxists.org/subject/china/documents/cpc/cc_gpcr.htm.

3 See Wang (2001) for a discussion of the impact of the Cultural Revolution on the education sector, including detailed descriptions of the consequences for specific universities and faculty. Professor Wang also maintains a website at the University of Chicago (hum.uchicago.edu/faculty/ywang/history/) that contains a great deal of information on the Cultural Revolution and provides biographies of many of the victims.
} 
function, and the resulting opportunity cost for China's economic development was enormous. It is conservatively estimated that because of the Cultural Revolution, China suffered a loss of 100,000 potential graduate degree holders between 1965 and 1976, along with a loss of one million qualified undergraduates and two million specialized secondary graduates (Song, 2009).

In December 1978, two years after Mao's death, China entered a historical turning point when Vice Premier Deng Xiaoping proposed a comprehensive transformation of China's society and economy. ${ }^{4}$ This policy shift, which went under the names of "Chinese Economic Reform" or "Economic Reform and Open Up Policy," effectively sparked the transformation of China that eventually led the country to become one of the world's largest economies. A key component of Deng Xiaoping's proposal, known as the Four Modernizations, was the long-term goal of modernizing China's agricultural, industrial, scientific, and technological sectors.

Vice Premier Xiaoping's proposed reforms had a profound impact on China's education system. In particular, the government began to encourage the best and brightest Chinese students to study abroad, and particularly to enroll in universities located in Western industrialized countries. In June 1978, for example, at a conference meeting with professors from Tsinghua University that took place just a few months before the formal introduction of the Chinese Economic Reform, Vice Premier Xiaoping emphasized that: 5

I highly support and encourage a quick increase in the number of overseas Chinese students, since this will be one of the most essential ways to accelerate the development of our outdated technology.

As part of the reforms, Deng Xiaoping made a strategic (and historic) decision to send 3,000 Chinese students annually to study in different countries, including the United States. Besides directly sending these government-sponsored and government-funded students, the Vice Premier encouraged outstanding Chinese students to study abroad by applying for teaching and research assistantships available in foreign institutions. Doctoral

\footnotetext{
${ }^{4}$ Deng Xiaoping was the key leader in China from the late 1970s to the early 1990 s. Immediately following the introduction of the reforms, Chinese-U.S. diplomatic relations were formally established in January 1979, opening up a new chapter in Sino-American relations.

${ }^{5}$ Chen (2007), p. 30.
} 
programs in the United States quickly began to receive many such applications for admission, and these programs became among the most generous in admitting and welcoming such students. The exogenous supply shock sparked by the Deng Xiaoping reforms was dramatic. China had sent nearly zero students to study in American universities between the 1950s and the late 1970s. By the late 1980s, however, China had become the leading sender of international students to the United States. ${ }^{6}$ In the 19891990 academic year, for example, China accounted for 33,000 (or 8.6 percent) of the 387,000 international students in the country.

This paper examines the impact of the supply shock of Chinese graduate students in a specific field, mathematics, on a specific country, the United States, where the available data allow us to comprehensively describe the impact of the shock on knowledge production in the field. Figure 1 illustrates the number of Chinese doctoral students in mathematics graduating from American institutions between 1960 and 2004. It is evident that there was a dramatic increase in the number of Chinese doctoral recipients sometime in the late 1980s, as the impact of the reforms initiated by Deng Xiaoping took hold. In fact, the number of doctoral degrees awarded to Chinese students increased almost six-fold, from 65 to 381, between 1980 and 1990. ${ }^{7}$

It is obviously difficult to pinpoint a specific date when the supply shock began to be fully felt in the production pipeline for mathematics doctorates in American universities. After all, it probably took at least a year or two for the reforms initiated by Deng Xiaoping to "filter down" and influence student behavior in the vast country of China. It would also take another year or two for these students to establish the credentials, work through the application process, and be accepted by American universities. And it would take another 6 years or so for the accepted students to actually complete their course work, to write their dissertation, and to receive their doctoral degree. Given these obvious and inevitable time lags, it is not surprising that the (higher) number of Chinese mathematicians graduating from American universities did not stabilize until around 1989, towards the end of the

\footnotetext{
${ }^{6}$ Institute of International Education (2013) and Institute of International Education (2009).

${ }^{7}$ We describe the methodology for identifying the sample of Chinese doctoral recipients in the next section. It relies on a match between the surname of the recipient and a comprehensive list of Chinese surnames.
} 
decade. The data illustrated in Figure 1 strongly confirm the existence of an exogenous supply shock (with a lag) resulting from the Deng Xiaoping-initiated reforms.

\section{Data}

We employ data drawn from three distinct sources to identify the ethnic background and track the professional careers of mathematicians in the United States. First, we have access to a database listing all papers published in mathematics and related fields. This exhaustive listing of mathematics publications is compiled and maintained by the American Mathematical Society (AMS) at MathSciNet, and is available for the period between 1939 and the present. Second, we have access to data collected by the Mathematics Genealogy Project (MGP), a database that matches advisors and advisees in mathematics doctoral programs since the 1300s. Finally, we use a database of ethnic names that allows us to identify the Chinese heritage of the mathematicians in our sample.

In addition to providing comprehensive coverage of the universe of academic papers published by mathematicians worldwide, the AMS data has one feature that makes it particularly useful in the present context: The professional staff at the AMS assigns each published mathematician a unique author identifier that follows a particular person throughout his or her career. The availability of these (carefully assigned) unique identifiers solves the problem of distinguishing the research profiles of authors who have similar names or initials. We have access to a version of the AMS database aggregated at the author, year of publication, and field of research level. For each author-year-field cell, the database reports the number of papers published, as well as the number of citations that those papers eventually earned from top journals in mathematics after the year 2000. Our version of the AMS database covers all papers published between 1939 and the first half of 2010, and was first used in Borjas and Doran (2012).

The MGP data reports the name of each doctoral degree holder in mathematics, the name of the advisor, the year the degree was earned, the institution that granted the degree, and the country where that institution is located. ${ }^{8}$ Crucially, it also contains an

\footnotetext{
8 The MGP is a worldwide database. The degree in question may then depend on the cultural or educational context. In most cases, the degree is a Doctor of Philosophy, but it may also be a Doctor of Science,
} 
administrative match between the advisors and advisees and the unique author identifiers in the AMS database. In other words, by using the unique author identifier we have access to the history of published output produced by the advisors and advisees identified in the MGP data.

To determine the scope of the coverage of the MGP advisor-advisee matches and the thoroughness of the match with the AMS data, we compared the degrees reported in the MGP file to the degrees listed in the annual census of new mathematics doctoral degrees awarded by North American universities and published annually by the American Mathematical Society. Using the published census as the "universe" of doctoral degrees in mathematics, we randomly chose 20 students from each of the following graduation years: $1980,1985,1990,1994,2000,2005$, and 2009. We found that the MGP file contained the relevant (and correct) information for between 85 and 100 percent of the degrees awarded in any given year, with an overall coverage rate of 93 percent. Furthermore, we found that only 2 percent of mathematics doctoral recipients should have been matched to the AMS unique author identifiers (because the author in question published a paper between 1939 and 2010), but were not. This robustness check of the underlying data, therefore, makes us confident that our matched MGP-AMS data has almost complete coverage of the universe of mathematicians either advising students and/or awarded a doctoral degree at the time of the Chinese supply shock.

Finally, we identify the Chinese heritage of the mathematicians in our sample by matching their surnames with a list of Chinese surnames. The source of Chinese surnames used in this paper is compiled in the genealogy section of FamilyEducation.com, the oldest and most visited website offering parental advice. In the context of this paper, this website is particularly useful because it provides a comprehensive list of the most common Chinese surnames. ${ }^{9}$ Many alternative lists of Chinese surnames, for example, only provide the top 100 surnames; the list available at Family Education is far more thorough, listing more than

a Candidate's Degree, etc. We will only be looking at degrees awarded in the United States, where the relevant degree is the Doctor of Philosophy.

${ }^{9} \mathrm{http}: / /$ genealogy.familyeducation.com/browse/origin/chinese. 
400 Chinese surnames. ${ }^{10}$ In addition, the Family Education database not only provides a phonetic system for transcribing the Mandarin pronunciations of Chinese surnames into the Latin alphabet (Pinyin), but also provides the phonetic system for transcribing the Cantonese pronunciations of Chinese surnames into the Latin alphabet (Jyutping). Because the Cantonese make up the largest group of Chinese immigrants to the United States, the inclusion of Cantonese Jyutping translations is particularly important to ensure that our identification of Chinese mathematicians misses few observations.

We classify a mathematician as having "Chinese heritage" (or, more conveniently, being "Chinese") if the mathematician's surname matches one of the surnames in the Family Education list. We merge the list of Chinese surnames available in Family Education with the MGP database to identify which advisors and advisees had Chinese ancestry. ${ }^{11}$

A potential problem with our approach to identifying the Chinese heritage of doctoral recipients is that it also "catches" U.S.-born persons of Chinese ancestry as well as foreign students born in Taiwan. There were no sudden changes in the birthrates of Chinese-Americans twenty-two years before the shock took place, making it unlikely that the supply increase shown in Figure 1 could be explained by a sudden rise in the number of Chinese-American students seeking to become professional mathematicians. Similarly, aggregate counts from the NSF census of doctorates indicates that around 30 to 40 doctoral degrees in mathematics were awarded annually to students born in Taiwan both before and after the opening of China, while the number of degrees awarded to persons born in the People's Republic of China rose from near zero in the early 1980s to around 200 in the early 1990s. In short, the rapid increase in the number of degrees awarded to Chinese students documented in Figure 1 was a direct result of the supply increase induced by the Deng Xiaoping reforms.

Table 1 uses our merged AMS-MGP data to calculate summary statistics on the number of doctoral degrees awarded in mathematics by American universities between

\footnotetext{
10 The top 100 Chinese surnames account for 85 percent of China's population, so that a list of 400 surnames is quite comprehensive (Lafraniere, 2009).

11 Although using surnames to construct the sample of mathematicians with Chinese heritage is not ideal, we randomly sampled 200 of the identified Chinese advisors and Chinese advisees and manually checked their profiles in MathSciNet. More than 95 percent of the mathematicians in this random sample were indeed Chinese (or Chinese-American).
} 
1975 and 2004. The data clearly show a sizable increase in the rate at which these degrees were produced between the first half and the last half of this period, with a disproportionately greater rise in the number of degrees awarded to Chinese students. The number of degrees awarded annually to Chinese students rose by over 300 percent between the pre- and post-1989 periods. However, the number of degrees awarded to American (i.e., non-Chinese) students rose by only 59 percent. Equally important, the Chinese students gravitated heavily towards Chinese advisors throughout the entire period. A Chinese student had a 13.2 percent probability of being mentored by a Chinese-American advisor, as compared to only a 3.4 percent probability for the typical American student.

Table 2 reports summary statistics for the sample of advisors that we will use in the empirical analysis reported below. The construction of the sample requires that these advisors mentored at least one doctoral student in the United States between 1975 and $2004 . .^{12}$ In addition, we restrict the analysis to the "pre-existing" stock of professional mathematicians, so that the advisors in our sample must have published at least one paper before 1986.13

The table reports statistics for two distinct groups: the advisors who have Chinese heritage and the residual sample of advisors who did not have Chinese heritage. For expositional convenience, we will refer to the advisors in the latter group as "American advisors," although it is obvious that this sample includes advisors of various ethnicities, and some were born outside the United States. ${ }^{14}$ Note that by restricting the sample to "pre-existing" advisors, we will be focusing on how the influx of Chinese graduate students affected the productivity of mathematicians who had established professional careers prior to the supply shock.

\footnotetext{
12 We define mentoring a student at an American institution as the union of: (a) being listed as the Ph.D. advisor for a fully matched recipient of a Ph.D. degree (i.e. a person that was administratively matched in both the MGP and AMS data); and (b) the MGP information for that degree reports that it was granted by an institution located in the United States.

13 By using 1986 as the year that defines the pre-existing group of mathematicians, we avoid the possibility that the group of "Chinese-American" advisors could include many of the Chinese foreign-born students who were themselves part of the supply shock, but who chose to remain in the United States after getting their degree rather than return to the People's Republic of China.

14 The number of foreign-born advisors in our sample is likely to be relatively small. The NSF census of doctorates reports that only around 20 percent of doctoral degrees in mathematics awarded prior to 1986 were granted to foreign-born persons.
} 
The statistics reported in Table 2 show that the pre-existing Chinese and American advisors published roughly the same number of papers and mentored roughly the same number of students prior to 1989. Specifically, the advisors of Chinese heritage published 1.5 papers per year, mentored 0.17 students per year, and each published paper received an average of 5.7 citations. Similarly, the American advisors published 1.4 papers per year, mentored 0.18 students, and received 6.1 citations.

The professional experience of the two groups, however, changed noticeably after the supply shock. The publication rate of the Chinese advisors increased to 1.7 papers per year, while that of the American advisors declined slightly to 1.3 papers. There was also a change in the production of students: the Chinese-American advisors, on average, began to mentor a few more students more per year than the American advisors (0.26 students versus 0.23 students), and some of this increase is obviously attributable to a surge in the number of Chinese students mentored. The different experiences of the two groups of advisors after the supply shock presage the productivity effects that are reported and examined in the remainder of this paper.

\section{The Productivity of Advisors}

We use a difference-in-differences strategy to document the impact of the supply shock of Chinese graduate students on the productivity of mathematics advisors in American universities. Specifically, we compare the change in productivity, however defined, between the advisors most affected by the shock and the advisors least affected by the shock, before and after the shock.

It is instructive to begin with the simplest specification. It is possible that ethnic complementarities between Chinese-American advisors and Chinese graduate students could easily generate knowledge spillover effects for this pool of mathematics advisors, and that the productivity consequences would likely be different for the advisors that did not have Chinese heritage. For example, if it were easier for Chinese advisors to interact and communicate with Chinese graduate students because of linguistic or cultural reasons (and vice versa), the Chinese-American advisors would be in greater demand for mentoring services after the supply shock. The increased size of the advisee pool could, in turn, affect 
both the quantity and quality of the published output of Chinese advisors, either through an increase in the number of collaborations or through knowledge spillovers on their own research program.

Our data consists of a panel constructed at the advisor-year level. The data, therefore, tracks the productivity of a particular advisor over time, and the panel allows us to relate the change in productivity to the supply shock of Chinese graduate students. The data consists of the 219 Chinese-American advisors and 5,277 American advisors first introduced in Table 2. Recall that all of these mathematicians published their first paper prior to 1986, so that the sample represents the pre-existing stock of potential mathematics advisors in American universities. The panel tracks the productivity of these advisors in each year over the 1975-2004 period.

To assess whether the supply shock had any relative productivity effects, we first estimate the regression model:

$$
y_{i t}=\alpha X_{i t}+\phi_{i}+\phi_{t}+\gamma\left(C_{i} \times T\right)+\varepsilon,
$$

where $y_{i t}$ measures the productivity of advisor $i$ at time $t$; $\phi_{i}$ represents a vector of advisor fixed effects; $\phi_{t}$ represents a vector of year fixed effects; $X_{i t}$ is a vector of standardizing variables; $T$ is a dummy variable indicating if the observation is observed in the post-shock period (defined as 1989 or beyond); and $C_{i}$ is a dummy variable indicating if advisor $i$ is Chinese-American. ${ }^{15}$ The variables included in $X$ control for the advisor's years of work experience (defined as a vector of fixed effects giving the number of years elapsed since the advisor's first publication in 5-year bands).

Note that the regression adjusts for individual-specific fixed effects in productivity, as well as for any calendar year fixed effects that affect the productivity of all advisors equally. We estimate equation (1) using various alternative measures of advisor productivity. All standard errors are clustered at the advisor level.

\footnotetext{
15 We estimated the regression models using alternative values for the specific year of the supply shock (e.g., 1986, 1987, or 1988). The qualitative nature of our evidence is robust to the choice of a particular date.
} 
Panel A of Table 3 reports the regression coefficient $\gamma$ from the basic regression specification in equation (1). This coefficient measures the difference-in-differences estimate of the impact of the supply shock on the productivity of Chinese advisors relative to American advisors. It is slightly positive and insignificant when the dependent variable is the total number of students mentored. However, this weakly positive point estimate masks a substantial change in the ethnic composition of the advisees of Chinese-American advisors. The number of Chinese students mentored by the Chinese-American advisors rose by 0.075 (with a standard error of 0.016), while the number of American students mentored fell by 0.047 (0.015). It seems, therefore, that while the supply shock only slightly increased the number of advisees mentored by the typical Chinese-American advisor, it certainly increased the probability that those students were Chinese.

The simple specification in equation (1), however, ignores the possibility that there is an important heterogeneity in the baseline group of American advisors. After all, some of those advisors worked in departments that received large numbers of Chinese students, while some worked in departments that were not heavily affected by the influx. Not surprisingly, there is one variable that helps to explain much of the departmental variation in the number of Chinese students that enrolled after the supply shock: Chinese students gravitated towards departments that already had Chinese-American advisors in their employ.

Suppose we classify mathematics departments into two types: "mixed" and "nonmixed." To illustrate our construction of these two types of departments, consider initially the simplest possible approach. We define a mixed department as one where a ChineseAmerican advisor supervised at least one doctoral thesis in the 1981-1985 period. ${ }^{16}$ Note that because of the lag in the production of a dissertation, this definition essentially implies that a mixed department employed an active Chinese-American mathematician sometime between the mid-1970s to the early 1980s. The residual group of departments that did not employ any active Chinese-American mathematicians would then give the non-mixed

\footnotetext{
16 We replicated the empirical analysis reported below using alternative definitions of a mixed department by varying the period in which we need to observe a Chinese-American mathematician actively mentoring a student, including 1976-1985 and 1971-1980. The results presented below are representative of the evidence resulting from these other specifications.
} 
departments. Around 20 percent of mathematics departments in the United States were mixed departments according to this classification.

A more stringent definition would be one that requires a higher level of supervising activity by Chinese-American advisors. We define an alternative definition of a mixed department as one where Chinese-American advisors supervised at least 3 doctoral dissertations in the 1981-1985 period. This definition implies that 6 percent of mathematics departments were mixed departments.

Figure 2 uses this more stringent definition of a mixed department and shows that the supply shock of Chinese graduate students was much larger in the departments that had a history of "frequent" advising by Chinese-American mathematicians. The (perschool) annual number of degrees awarded to Chinese students by the non-mixed departments increased by only about 0.6 students per year between the 1980 s and the 1990s, as compared to an increase of around 6 students per year for the departments that had a frequent Chinese presence.

This differentiation between departments implies that we can now think of three distinct groups of advisors: Chinese-American advisors; American advisors who were affiliated with a mixed department as of 1988 (just prior to the time that the variable indicating the supply shock "turns on"); and American advisors affiliated with a non-mixed department as of $1988 .{ }^{17}$ Depending on whether we use the more or less stringent definition of a mixed department, either 15.3 or 37.8 percent of American advisors were affiliated with a mixed department as of 1988. As Figure 2 makes clear, American advisors in the mixed departments were far more likely to be affected by the supply shock than American advisors in the non-mixed departments.

The expanded regression model can then be written as:

$$
y_{i t}=\alpha X_{i t}+\phi_{i}+\phi_{t}+\gamma_{C}\left(C_{i} \times T\right)+\gamma_{M}\left(A_{i}^{M} \times T\right)+\varepsilon,
$$

17 More precisely, we use the affiliation of the last dissertation supervised as of 1988 to determine if an American mathematician is employed by a mixed or a non-mixed department. In the small number of cases where a mathematician had not yet supervised a thesis as of that date, we backdate the affiliation of the first post-1988 thesis. 
where $A_{i}^{M}$ is a dummy variable indicating if advisor $i$ is an American advisor employed in a mixed department in 1988. ${ }^{18}$ The omitted group in equation (2), of course, is the group of American advisors employed in non-mixed departments. The coefficient $\gamma_{C}$ in equation (2) now gives the difference-in-differences estimate of the impact of the supply shock on the productivity of Chinese advisors (relative to American advisors in non-mixed departments), while the coefficient $\gamma_{M}$ measures the corresponding impact on the productivity of American advisors in mixed departments.

As with the simpler specification in equation (1), we would expect ethnic complementarities in knowledge production to increase the productivity of Chinese advisors, so that $\gamma_{C}$ would be positive. However, the potential impact on the productivity of the American advisors employed by the mixed departments is less clear-cut. These advisors could perhaps benefit from the presence of additional Chinese students, although it seems reasonable to suspect that the spillovers would be weaker than those affecting the Chinese advisors in those same departments. Such a differential spillover effect could arise, for example, if Chinese advisees are more likely to coauthor with Chinese advisors than with American advisors. The influx of Chinese students could also affect the size of the potential advisee pool for American advisors in an indirect way. For example, if the admission of Chinese graduate students crowds out American graduate students, the supply shock might shrink the number of students that American advisors could mentor and collaborate with.

Finally, there is little reason for the supply shock to have much of an impact on the productivity of American advisors working in the non-mixed departments, which serves as the control group in the regression model. As Figure 2 indicates, this group of advisors was not particularly affected by the supply shock because the non-mixed departments attracted relatively few Chinese graduate students after the opening up of China. The impact on the productivity of American advisors employed by such departments would most likely be

18 Note that the variable $A_{i}^{M}$ is not indexed by $t$, so that the regression captures the reduced-form effect of being initially employed in a non-mixed department, regardless of whether the mathematician remained in that department or moved elsewhere at some point after the supply shock. 
composed of second-order effects, resulting from feedback mechanisms in the academic marketplace.

Panels B and C of Table 3 report the estimates of the coefficients $\gamma_{C}$ and $\gamma_{M}$ using the two alternative definitions of a mixed department. To simplify the exposition, we will mainly discuss the coefficients summarized in Panel C, which uses the more stringent definition. The qualitative nature of the evidence, however, is robust to the definition used.

Consider initially the regression where the dependent variable is the total number of students produced by an advisor in a particular year. As with the simpler specification discussed earlier, the supply shock of Chinese graduate students did not lead to a sizable increase in the number of students that the Chinese advisors produced. The coefficient $\gamma_{C}$ is again positive and insignificant, with a value of $0.026(0.022)$. However, the impact of the supply shock on the number of students produced by American advisors in the mixed departments is slightly negative (but insignificant). In other words, although the supply shock seemed to slightly increase the total number of students produced by Chinese advisors, it also seemed to slightly reduce the number produced by the American advisors in the mixed departments.

The next two columns of Table 3 illustrate the underlying mechanism behind these results. Specifically, they report the impact of the supply shock on the number of Chinese and American students mentored, respectively. It is evident that the supply shock increased the relative number of Chinese students produced by Chinese advisors; the coefficient is 0.077 (0.016). At the same time, however, the supply shock reduced the relative number of American students mentored by these advisors; the coefficient is - 0.050 (0.015). The magnitude of the regression coefficients implies that the increased number of Chinese students mentored by the Chinese-American advisors was almost offset by a reduction in the number of American students mentored. In other words, the supply shock led to a substantial ethnic redistribution of mentoring activities by the Chinese-American advisors - away from American students and towards Chinese students.

At the same time, the American advisors in mixed departments saw both an increase in the number of Chinese students mentored (relative to the control group), and a somewhat larger decline in the number of American students mentored. The net decline in 
the production of advisees by American advisors in the mixed departments, therefore, is entirely due to the fact that the supply shock of Chinese graduate students seems to have reduced the number of American students that they could mentor.

It is instructive to illustrate the raw data that underlies these results on the production of students. Figures 3 and 4 illustrate the trend in the "unexpected" number of students mentored after the supply shock. In particular, we calculate for each advisor the average annual number of Chinese advisees (in Figure 3) or American advisees (in Figure 4) before 1989. We then calculate a residual giving the difference between the actual number of students that the advisor supervised each year and the number that would be expected from their pre-1989 activities. The figures dramatically show the unexpected increase in the number of Chinese students mentored by Chinese advisors in the postshock period, as well as the relative decline in the production of American students by American advisors employed in the mixed departments.

The last two columns of Table 3 continue our analysis by estimating the regression model using two additional measures of output: the number of papers produced in a given year and the number of citations per paper published that year. Consider initially the results on the quantity of published output. The regression coefficients clearly indicates an increase in the relative number of papers published by Chinese advisors in the post-shock period; the coefficient in Panel C is 0.167 (0.089). Put differently, the supply shock increased the number of papers published by the typical Chinese advisor by around 1.7 papers over a 10-year period (relative to the output of American advisors in the control group). At the same time, the supply shock led to a relative decline in the number of papers published by the American advisors in the mixed departments-a decline of more than a half-a-paper over the decade. In sum, relative to the control group that was presumably least affected by the influx of Chinese students, the Chinese-American advisors began to publish more and their American colleagues in the mixed departments began to publish less.

Figure 5 illustrates the raw data that underlies these regression results. Specifically, the figure again shows the trend in the "residual" that results from differencing an advisor's annual number of papers from the average number of papers he or she published prior to 1989. The figure clearly documents the rise in the publication rate of Chinese-American 
advisors and the absolute and relative decline in the publication rate of American advisors employed in the mixed departments.

It is important to note, however, that the productivity effects of the supply shock seem to be restricted to the quantity of published output, rather than the quality of the output. The regression analysis reported in the last column of Table 3 does not provide any evidence to indicate that the supply shock had an impact on the number of citations received by the papers written by the typical advisor in any of the groups, regardless of whether the advisor is Chinese or American, or whether the advisor works in a mixed or non-mixed department.

To summarize, the supply shock of Chinese graduate students sparked by the opening of China led to: (a) an increase in the number of Chinese students mentored and an increase in the number of papers published by the pre-existing group of Chinese-American advisors employed in American universities; and (b) a decrease in the number of students, specifically American students, and a decrease in the number of papers published by the pre-existing group of American advisors in the departments that were most likely to attract the Chinese graduate students. The remainder of this paper shows that these reduced-form results are consistent with the hypothesis that there exist strong ethnic complementarities in knowledge production in an institutional setting where the size of departments is roughly fixed so that the influx of Chinese graduate students led to a crowdout of American graduate students.

\section{Ethnic complementarities in production}

The evidence suggests that the supply shock of Chinese graduate students affected both the number of students mentored by an advisor and the advisor's publication productivity, and that these effects differed between the pre-existing advisors who had Chinese heritage and those who did not. It is easy to imagine how this differential effect in publication productivity might arise. The exogenous shift in the size and composition of the pool of advisees induced by the opening of China changed the sphere of the advisor's network of potential collaborations. It is not unusual in many sciences for advisors to coauthor at least one paper with their students. Further, Freeman and Huang (2014) 
document that academic collaboration tends to follow ethnic lines. It would not then be surprising to find that as the pool of Chinese graduate students in the United States increased, the Chinese-American advisors would produce more papers because of an increased probability of coauthoring with their ethnically similar students. Even in the absence of any additional collaboration opportunities, the increased size of the Chinese advisee pool could influence the advisor's research activity in less direct ways. The Chinese-American advisor may suddenly see paths to research questions that were clouded prior to his interaction with the students.

It is easy to imagine why advisors and advisees might be complements in the production of a particular advisor's research output. The advisor's experience and knowhow clearly increases the productivity of the student. Similarly, the process of mentoring and teaching, as well as the new perspectives introduced by the advisee, cannot help but influence the advisor's research activities. The key question in the context of this paper, however, is whether such complementarities are stronger when the advisors and the advisee share an ethnic background.

Suppose the production function for a particular advisor's research output, $Q$, has two inputs: $X_{1}$ and $X_{2}$, measuring the time inputs of the advisor and advisee, respectively. The advisee's time input, however, is "filtered" through the fact that the advisor and advisee may or may not share the same language, culture, and other relevant characteristics. As a result, the advisee's "effective" time input may differ from the advisee's actual time input $X_{2}$.

Define the effective time input as $X_{2}^{\eta}$, where the exponent $\eta(\eta \geq 0)$ measures the "ease" with which the personal and intellectual communications between the advisor and advisee occur. Of course, the value of $\eta$ is specific to any particular advisor-advisee match. For example, the value of $\eta$ for a match between a Chinese advisee and a Chinese advisor may be different (and perhaps larger than) the value of $\eta$ for a match between the same Chinese advisee and a non-Chinese advisor. In short, the similarities or differences in the vector of characteristics that determine the ease with which an advisor and an advisee interact can either amplify or contract the actual value of any particular time input by the advisee. 
We write the CES production function specifying the process of producing the advisor's mathematical output as:

$$
Q=\left[\alpha_{1} X_{1}^{\delta}+\alpha_{2}\left(X_{2}^{\eta}\right)^{\delta}\right]^{\frac{1}{\delta}}
$$

where $\delta=1-1 / \sigma$, and $\sigma$ is the elasticity of substitution between the advisor and the advisee. It is convenient to interpret the supply shock of Chinese graduate students as an increase in $X_{2}$. Let $M P_{1}$ be the marginal product of the advisor's time input in the production of his or her mathematical output. It is then trivial to show that:

$$
\frac{d \log M P_{1}}{d \log X_{2}}=\frac{1}{\sigma} s_{2} \eta
$$

where $s_{2}$ is the share of output attributable to the advisee input $\left(s_{2}=\alpha_{2}\left(X_{2}^{\eta}\right)^{\delta} / Q^{\delta}\right)$. Note that a supply shock of advisees will increase the marginal product of the advisor as long as advisors and advisees are not perfect substitutes $(\sigma<\infty)$. Note also that the complementarity in equation (4) is stronger the greater the value of the parameter $\eta$. In other words, any characteristics of the match that increase the effective value of an advisee's time input are profitable to the advisor. It would then be reasonable to expect that advisors and advisees make pairings that specifically increase the value of $\eta$, and to find that such pairings increase the advisor's productivity. ${ }^{19}$

To determine the intensity of the complementarities arising from shared ethnicity, we now examine the coauthorship patterns of the pre-existing Chinese and American advisors in our data. Specifically, we manually collected the entire coauthorship history for each of the 219 pre-existing Chinese-American advisors in our sample, so that we are able to determine if any given coauthorship involved an advisee and if that advisee was a

19 Although it is easy to generalize the model to examine how the time input of advisors responds to the supply shock, we do not pursue this generalization because we do not have any data that would allow us to more carefully examine the inputs associated with any particular advisor-advisee pairing. 
Chinese student. We also manually collected comparable data for a random sample of 213 American advisors. ${ }^{20}$

Consider a particular pairing between advisor $i$ and advisee $j$. For any $(i, j)$ pairing, our data allows us to determine if the pair coauthored at any point during their careers, and we can also count the number of papers coauthored by the specific pair. We can then estimate regressions of the type:

$$
z_{i j}=\alpha X_{i t}+\beta_{1} C_{i}+\beta_{2} C_{j}+\beta_{3}\left(C_{i} \times C_{j}\right)+\varepsilon,
$$

where $z_{i j}$ is a variable describing the degree of collaboration between advisor $i$ and advisee $j$; and $C_{i}$ and $C_{j}$ are dummy variables indicating if the advisor or advisee are Chinese, respectively. The coefficient of interest in this regression is $\beta_{3}$, which tells us if a collaborative relationship between an advisor and an advisee is more likely to occur when both parties share a Chinese heritage. The regression also includes a variable indicating the calendar year in which the $(i, j)$ pairing was formed. We estimate the regression model using two alternative dependent variables: (a) a dummy variable indicating if pair $(i, j)$ ever collaborated; and (b) the number of coauthored papers resulting from a potential collaboration. The standard errors of the coefficients are clustered at the advisor level.

Table 4 reports the regression coefficients from the basic model in equation (5), as well as from an expanded specification that also includes advisor-specific fixed effects. The regressions clearly show that the matching of a Chinese advisor and a Chinese advisee is far more likely to lead to a collaboration that resulted in a published paper than any other pairing. ${ }^{21}$ In fact, the probability of a successful collaboration increases by about 17 percent when the two parties in the pair are Chinese, regardless of whether or not advisorspecific fixed effects are included in the regression. The matching of a Chinese advisor and

\footnotetext{
${ }^{20}$ In fact, we collected the collaboration networks for a random sample of 250 American advisors, but the effective sample was reduced to 213 observations after imposing the various sample restrictions.

21 It would be interesting to compare the extent of collaboration between a Chinese advisor and a Chinese advisee to that observed between a type- $k$ advisor and a type- $k$ advisee, where $k$ indexes a particular ethnic background. Unfortunately, the available data do not allow us to identify the specific ethnic background of the vast majority of mathematicians.
} 
a Chinese advisee generates about one additional paper for the pair relative to the number of coauthored papers published by any other ethnic coupling between advisor and advisee.

Given the importance of intra-ethnic coauthorship, it is instructive to determine how much of the effect of the supply shock on the rate of publication documented in Table 3 can be attributed to increased (or decreased) collaboration with advisees, and how much of it may be due to other types of research activity. To address this question, we use the information we collected on the authorship of every single paper published by the 219 Chinese-American advisors in our sample, as well as the 213 randomly chosen American advisors.

Because of the relatively small number of observations, we aggregated the data into two periods-before and after 1989. We then calculated the average number of papers published annually in each of the two periods for each of the three groups of advisors (i.e., Chinese advisors, American advisors in mixed departments, and American advisors in nonmixed departments). We also calculated the average number of papers resulting from alternative collaboration arrangements. We then estimated a simpler version of the regression model in equation (2) to measure the pre-post difference in the rate of output for each type of arrangement. Table 5 summarizes the results of this regression-based decomposition by reporting the coefficient of the interaction variable between the post1989 indicator and the type of advisor. ${ }^{22}$

As first noted in the previous section, the number of papers published by ChineseAmerican advisors rose rapidly between the pre- and post-shock periods. The average Chinese advisor published almost 0.3 more papers per year after 1989 than before 1989. The change in the publication rate for American advisors in the non-mixed departments (the group of advisors that presumably forms the control group) was somewhat smaller, a rise of only 0.2 papers per year. In contrast, the publication rate of American advisors affiliated with mixed departments rose by only 0.1 papers per year.

\footnotetext{
22 Because we are looking at variation in the rate of publication across a diverse group of advisors over long periods (1975-1988 and 1989-200), we use an experience-adjusted measure of output as the dependent variable in order to adjust for the advisor's age. The experience-adjusted measure is given by the residuals from a first-stage regression where the left-hand-side is the average number of papers published by an advisor during each period and the regressors are fixed effects measuring the advisor's years of work experience (in 5-year bands).
} 
These net changes for the three groups disguise a lot of variation in the way that the productivity shifts occurred. Among Chinese advisors, for example, the data indicate that part of the increase in the rate of output results from increased coauthoring with Chinese advisees and with other Chinese mathematicians. The additional Chinese-Chinese collaborations increased the average number of papers published annually by around 0.15. Of course, neither group of American advisors was able to improve their productivity due to Chinese coauthorship by anything resembling this rate: Increased coauthoring with Chinese mathematicians increased the number of papers by 0.02 for Americans employed in mixed departments and by 0.04 for Americans employed in the non-mixed departments. American advisors in mixed departments, however, were able to increase the number of papers they published with their American advisees despite having fewer such advisees.

The data also illustrate the continuing trend towards less solo-authored work and more coauthored work among mathematicians. Interestingly, all three groups experienced a decrease in the amount of solo-authored work by between -0.06 and -0.13 papers per year during the period. Note, however, that Chinese advisors were able to more than offset the decline in solo-authored work with a sizable increase in "other" coauthoring. The American advisors employed in mixed departments seemed particularly unable to take advantage of opportunities for increased coauthoring with other mathematicians. This effect may be due to specialization of roles within a department: faculty who have a harder time finding advisees to mentor may be asked to perform more service and administrative tasks. In the long run, this reallocation of administrative responsibilities could easily result in less research output for the affected professors.

The strong role played by intra-ethnic collaborations and the exogeneity of the supply shock of Chinese graduate students suggest that we can revisit the reduced form evidence reported in the previous section and attempt to estimate the causal effect of mentoring an additional student on an advisor's productivity. In particular, consider the following regression relating the number of papers that advisor $i$ publishes in year $t, P_{i t}$, to the size of an advisor's "collaboration pool":

$$
P_{i t}=\phi_{i}+\phi_{t}+\beta \tilde{N}_{i t}+\alpha X_{i t}+\varepsilon
$$


We define the collaboration pool $\tilde{N}_{i t}$ as the total number of students that the advisor has supervised in the five-year span between years $t-3$ and $t+1.23$ We estimate equation (6) by using instrumental variables, where the instruments are the interaction terms $\left(C_{i} \times T\right)$ and $\left(A_{i}^{M} \times T\right)$ employed in the reduced-form regressions reported in Table 3 (i.e., the interactions between the post-1989 indicator, $T$, and dummy variables indicating if the advisor is either Chinese-American or an American affiliated with a mixed department).

Table 6 reports the coefficients from alternative specifications of the regression model (using the entire sample of 5,496 mathematics advisors). Panel A of the table uses the definition of a mixed department that requires the supervision of at least one thesis by a Chinese-American advisor, while the bottom panel uses the more stringent definition that requires the supervision of at least three dissertations by Chinese-American advisors. The regressions reported in the first column define the collaboration pool $\tilde{N}_{i t}$ in terms of the total number of students supervised (in the five-year period), regardless of ethnicity. The second column explicitly accounts for the ethnic-based spillovers and defines the collaboration pool as the total number of ethnically similar students supervised (i.e., the number of Chinese students supervised by the Chinese advisors, or the number of American students supervised by the American advisors).

Regardless of the instrument used, it is obvious that the first-stage regression model that specifically accounts for the intra-ethnic spillovers does a far better job of predicting the size of the advisor's collaboration pool (i.e., the Angrist-Pischke multivariate $F$ test of excluded instruments is significant, with $p$-values of 0.0001). The estimate of the secondstage coefficient $\beta$ in equation (6) hovers around 0.5 , indicating that the exogenous and sudden appearance of an additional student in an advisor's collaboration pool increases the advisor's rate of publication by about half a paper. In short, the evidence unambiguously shows that supply shocks which expand the potential for intra-ethnic collaborations will raise the productivity of the pre-existing advisors in the affected ethnic group substantially.

\footnotetext{
23 Our results are very robust to alternative definitions of the pool (such as a 3-year or 7-year aggregate). We use a one-year lead in the aggregation to allow for the possibility that the advisor is collaborating with current students who will soon graduate.
} 


\section{Crowdout Effects}

The decision by an American mathematics department to admit Chinese doctoral students obviously depends on many factors, including the relative quality of the applicants, the possibility that Chinese students pay for a higher fraction of their education, the widespread acceptance of the axiom that "diversity" is beneficial in a university setting, and the relative marginal products of the American and Chinese students as university employees (because many graduate students typically work as research or teaching assistants). Some of these factors might imply that admission officers might prefer to admit a Chinese student over an American applicant, even if the two applicants had the same observable qualifications.

The offer of admission to Chinese graduate students alters the educational opportunities available to similarly qualified Americans in two distinct ways. First, the number of slots available in a particular doctoral program may be relatively fixed, at least in the short run. The enrollment of an additional Chinese student would then suggest that one fewer American student could be admitted. This is the simplest and clearest case of a crowdout effect. Even if the university were expanding and admitting more Chinese and more American students, there may still be a crowdout effect in the sense that American enrollment would have increased at an even faster rate if the university had not increased its supply of Chinese students.

The entry of large numbers of Chinese graduate students into American mathematics programs can also influence the enrollment decisions made by American students in a less direct way. It may alter the incentives for natives to pursue specific educational programs.

Suppose, for instance, that many of the Chinese students enrolled in mathematics doctoral programs remain in the United States after graduation..$^{24}$ If there were little crowdout in the university admissions process, one might then expect that the (eventual) larger supply of newly minted mathematicians would lower entry wages and the

\footnotetext{
24 The evidence, in fact, suggests that Chinese graduate students in both mathematics and other fields are consistently more likely to stay than the average foreign student in those fields; see National Science Board (2014), Appendix Table 3-22.
} 
occupation would become relatively less attractive to Americans. ${ }^{25}$ The Chinese students might still prefer to enter those low-paying jobs because their career decisions are mainly guided by the comparison of employment opportunities available in the United States and China. In contrast, American students might have many other career choices (e.g., a quant career in Wall Street), and would shy away from applying to programs in educational disciplines where foreign students cluster and subsequent wages are low. In the long run, this behavioral response would again imply that an exogenous increase in the enrollment of Chinese students in a particular program would reduce the number of Americans who would want to enroll in that program.

Note that the first of these two crowdout effects is specific to a particular university-and indicates how native enrollment in that institution changes as the number of foreign students enrolled in that institution increases. The second crowdout effect results from an economy-wide supply response that discourages natives from pursuing particular educational programs in all universities. The empirical analysis presented in this section nets out these economy-wide fluctuations and examines the shifts that occur in the enrollment of American students within a particular mathematics department as the size of the Chinese student population in that department grows.

To estimate the crowdout effect, we supplement our data with aggregate counts of doctoral degrees drawn from the public use version of the Survey of Earned Doctorates (SED). The SED contains a population census of all doctorates granted by a U.S. institution, and reports information on the field and year of degree, as well as on the degree recipient's ethnicity and citizenship status. We use these data to compute the number of degrees awarded in mathematics each year between 1975 and 2000, as well the number of degrees awarded to American citizens, to foreign students, and to foreign students of Asian heritage. 26

25 See Borjas (2009) for evidence that supply shocks of foreign students affect the earnings of newly minted doctorates in specific disciplines, and Borjas and Doran (2012) for related evidence on the competitive effects resulting from the influx of Soviet mathematicians. Freeman et al (2001) describe how shifts in the bioscience job market, shifts that are partly due to the influx of foreign students, affect career incentives in that sector.

26 The public use data are available at https://ncsesdata.nsf.gov/webcaspar/. The number of degrees awarded to American citizens closely approximation the number of degrees awarded to U.S.-born persons 
Let $A_{s t}$ denote the number of U.S.-born students awarded a degree in mathematics by university $s$ at time $t$, and let $C_{s t}$ denote the respective number of Chinese students. The generic regression model used to capture the crowdout effect is given by:

$$
A_{s t}=\phi_{s}+\phi_{t}+\theta C_{s t}+\varepsilon,
$$

where $\phi_{s}$ represents a vector of department fixed effects and $\phi_{t}$ represents a vector of year fixed effects. ${ }^{27}$ We estimate the regression model using all the available data between 1975 and 2000 for the subset of schools that produced at least one mathematics doctoral degree during the period. The standard errors are clustered at the department level to adjust for possible serial correlation in the error term within a particular institution.

The first row of Table 7 reports the estimate of $\theta$ from OLS regressions using alternative specifications of the model in equation (7). In particular, each of the columns in the table employs a different measure of "foreign students" as the regressor, including the total number of foreign-born doctoral recipients, the total number of foreign students of Asian ancestry, and the total number of Chinese foreign students. ${ }^{28}$ Regardless of the definition of the independent variable, the point estimates of $\theta$ are negative. The descriptive evidence provided by the OLS regressions, while imprecise, seems consistent with the presence of a crowdout effect.

because of the very long time lag required for a foreign student to achieve permanent residence status (a "green card") and then wait the prerequisite five years before filing a naturalization application.

27 The period fixed effects help to capture the potential crowdout that arises as natives respond to the changed labor market opportunities caused by an increase in the number of foreign students. Any adverse wage effects would presumably reduce the incentives of natives to enroll in a graduate program at any university.

28 The counts of foreign-born and foreign-born Asian students are drawn from the SED. The number of Chinese students is drawn from the matched AMS-MGP data files, and gives the number of students with a Chinese surname. The SED also collects restricted use data on the number of foreign students per institution per year who were specifically born in the People's Republic of China; we are currently seeking access to this data. Some of the regressions reported below use an IV strategy to identify the crowdout effect. As long as our instrument has a valid exclusion restriction and a strong first stage, the measurement error resulting from using either the SED count of foreign-born students of Asian ancestry or the number of students with a Chinese surname (instead of the number of students who were specifically born in the People's Republic of China) should not affect the coefficients of interest. 
One problem with interpreting the coefficient $\theta$ as an unbiased estimate of a crowdout effect is that the inclusion of the school-specific fixed effects in the regression model fails to account for a key factor: A few large and/or growing departments likely admit large numbers of American and Chinese students simultaneously. In fact, many of the Chinese graduate students who came to the United States after the opening up of China tended to gravitate to these large and growing departments. Put differently, there are school-year interaction fixed effects $\phi_{s t}$ that are positively correlated with both $A_{s t}$ and $C_{s t}$ in equation (7). The exclusion of these interactions from the regression model introduces a positive and spurious correlation between the number of foreign students in the righthand-side and the error term. As a result, the negative estimate of the crowdout effect reported in the first row of Table 7 likely underestimates the true impact of the supply shock on the enrollment of American students.

To net out the spurious correlation, we would need to specify the regression model in a way that lets us account for the idiosyncratic school-year "demand shocks." Obviously, the direct inclusion of school-year interaction fixed effects makes it impossible to identify the parameter $\theta$ in (7). One very simple way of bypassing the problem would be to find a regressor to proxy for the demand shocks. We used the SED to count the total number of degrees awarded outside mathematics by a university each year, and added this measure of the school-specific enrollment trends to the regression model. As the second row of Table 7 shows, adjusting for demand shocks in this rough fashion increases the magnitude of the crowdout effect: the point estimate in the last column is now $-0.233(0.074)$, so that approximately one American student "loses" his or her spot in a mathematics graduate program for every four Chinese students admitted.

Alternatively, we can find an instrument that induces changes in the number of foreign students admitted by a particular university that are independent from the schoolspecific demand shocks. Because the consequences of the Chinese supply shock were most evident in a subset of universities at a particular period of time, we can use the joint exogeneity of the definition of a mixed department and the timing of the supply shock to create such an instrument. In particular, we define the instrument as the product of the post-1989 indicator variable and the dummy variables indicating if the department was 
mixed (either the department had at least one active Chinese advisor prior to the supply shock between 1985 and 1985, or the department had at least three active Chinese advisors prior to the supply shock).

Panels B and C of Table 7 report the key coefficients from the two-stage IV models. Regardless of how we define the number of foreign students on the right-hand-side of equation (7) or which of the two instruments we use, the instrument has a very significant positive effect on the number of foreign students awarded degrees. In the last column, for instance, the coefficient is $1.848(0.400)$ when we use the less stringent definition of a mixed department.

The table also reports the IV estimates of the crowdout effect. It is evident that the crowdout coefficient $\theta$ is always negative, often statistically significant, and numerically sizable. In fact, we typically cannot reject the hypothesis that the crowdout coefficient is equal to - 1 in any of the specifications. Put differently, the IV regressions provide strong evidence that one American student was "displaced" for every Chinese graduate student admitted after the opening of China.

The strong crowdout effects reported in Table 7 allow us to provide a consistent explanation of the productivity results discussed in earlier sections. The influx of Chinese graduate students led to a corresponding reduction in the number of American students in mathematics departments. Because of ethnic complementarities, the Chinese graduate students were attracted to and matched with the pre-existing Chinese-American advisors, and the relatively fixed size of the pool of graduate students at the department level implied that fewer American students were available to the American advisors (perhaps accompanied with a drop in other resources). As we have shown, this redistribution helped generate important productivity effects in terms of published output, with the productivity of Chinese advisors increasing and that of American advisors employed in the mixed departments declining.

\section{Aggregate Effects}

Because the influx of Chinese graduate students created both winners and losers in the pre-existing pool of mathematics advisors, a crucial question arises: Did the gains to the 
winners outweigh the losses to the losers? This section reports the results from an empirical exercise that attempts to measure the size of the "surplus" resulting from the supply shock. It turns out that the aggregate decrease in productivity observed among American advisors was almost exactly offset by the aggregate increase in productivity observed among Chinese advisors.

To calculate the size of the surplus, we adopt a methodology introduced in Borjas and Doran (2012). Specifically, we compare the actual aggregate product produced with what would have been predicted from the pre-shock productivity profiles of each individual advisor. Suppose we again divide the pre-existing group of advisors into three categories: Chinese advisors, American advisors employed in mixed departments, and American advisors employed in non-mixed departments.

We estimated separate regression models that trace out the mathematician's ageproduct profile for each of these groups. Specifically, we estimated a regression of the number of papers published by a particular mathematician in a particular calendar year on years of experience (introduced as a fourth-order polynomial) and on a vector of individual fixed effects. We only use data from 1980 through 1988 to estimate the regression model, so that the path of the age-product profile is estimated using publication data prior to the supply shock. We then used these regressions to predict the post-1989 output of each mathematician. To ensure that we do not extrapolate into the far-off future, we conduct a "short-run" prediction exercise for the five-year period between 1989 and 1993. We then added the total number of predicted publications across years and across all mathematicians in each group. Table 8 reports the predicted total number of papers (per year) and contrasts these predictions with the actual output of the pre-existing advisors using the two alternative definitions of a mixed department.

Not surprisingly, the exercise reveals dramatic differences in how well the pre-1989 productivity history predicts the post-1989 output among the three groups. Consider, for instance, the group of American mathematicians employed in non-mixed departments. These mathematicians were the least likely to be influenced by the supply shock of Chinese graduate students. In fact, their pre-1989 productivity history predicts that they would publish 6,538 papers annually in the subsequent 5 years (using the more stringent definition of a mixed department). In fact, they published 6,545 papers, a difference of only 
7 papers. Put differently, the pre-1989 productivity history does an extremely good job of predicting future productivity for the least-affected group of American advisors.

Consider instead the group of Chinese-American mathematicians. Their pre-1989 productivity history would predict that they would publish 314 papers annually in the subsequent period. In fact, they published 380 papers, or 65 papers over the prediction. In contrast, the American advisors employed by mixed departments are predicted to publish 1156 papers, but published only 1092 papers, a "loss" of 64 papers. Given the evidence presented earlier in this paper, it is not surprising that the pre-shock productivity history tends to under-predict the actual productivity of Chinese advisors and over-predict the actual productivity of American advisors in mixed departments.

Notably, the aggregate effect again suggests the existence of a fixed-sized pie. In the simulation that uses the more stringent definition of a mixed department, for example, the prediction exercise predicts a total output of 8,007 papers annually, while the actual output was equal to 8,016 papers, an insignificant difference of only 9 papers.

The crucial lesson from these prediction exercises is that the total product of the pre-existing stock of mathematics advisors in the United States did not change as a result of the supply shock of Chinese students. The increase in productivity arising from ethnic collaboration and benefitting the pre-existing Chinese advisors was met with an equallysized decrease in productivity among the American advisors employed in those departments that attracted (and enrolled) most of the Chinese graduate students. In short, there is no evidence that the influx of Chinese graduate students greatly increased the aggregate output or that it improved the "quality" of the published work. The evidence instead seems consistent with the conjecture that the additional papers that were written by Chinese-American advisors are papers that would have been written by Americans in the mixed departments, but never were.

It is crucial to emphasize that although the total number of graduate student slots available to the pre-existing advisors can be thought of as being relatively fixed for institutional reasons, there is no mechanical constraint on the amount of research output that the sample of pre-existing American and Chinese-American advisors could have produced. If it were the case that the affected advisors comprised all of the mathematics professors publishing in English-language journals, and if English-language journals had 
exogenous space limitations, then our results showing a fixed-sized "mathematics pie" could be a numerical artifact of such restrictions. However, the research output that the affected advisors were producing comprised only a small fraction of the total Englishlanguage mathematical output before the shock, and an even smaller fraction of the output after the shock simply because many new mathematicians would continue to enter the profession after 1989. As a result, if the supply shock had indeed produced larger benefits for the Chinese-American advisors than the corresponding losses for their American colleagues, then the portion of the worldwide English-language "mathematics pie" that this group comprised could have potentially increased.

\section{The Productivity of the Students}

Up to this point, our analysis has focused on documenting the consequences of the supply shock for the productivity of the advisors. We have shown that there was a redistributional impact, but little evidence of an "efficiency" effect in the sense that the aggregate output of the pre-existing advisors remained fixed after the supply shock of Chinese graduate students. It is entirely possible, however, that the beneficial efficiency consequences of the supply shock might show up much later, after the Chinese doctoral students become professional mathematicians themselves. Their research efforts would, in turn, contribute to "the greater good" of mathematical knowledge. This section examines whether these long-run effects exist and are numerically important.

Specifically, we track the research output produced by the students of the sample of the 5,496 pre-existing Chinese-American and American advisors constructed in the previous sections. We again make use of the merged AMS-MGP data to create a new file containing the publication records of the 27,885 students mentored by these advisors between 1975 and 2004. We then estimated regression models that relate the student's

productivity (defined in various ways) to a variable indicating if the student was Chinese. The basic regression specification is:

$$
Y_{k t}=\phi_{t}+\gamma C_{k}+\varepsilon .,
$$


where $Y_{k t}$ measures the research productivity of student $k$ who graduated in year $t ; C_{k}$ is a dummy variable indicating if student $k$ is Chinese; and $\phi_{t}$ gives a vector of fixed effects indicating the year in which the doctoral degree was awarded.

We constructed several alternative measures of the student's productivity $Y_{k t}$. Table 9 summarizes the regression results. The first column reports the coefficient $\gamma$ from the basic specification in equation (8), while the other columns report the coefficient after the regression includes either school-specific fixed effects or advisor-specific fixed effects. Consider the regression coefficients reported in the second row, where the dependent variable indicates the average number of papers published annually by a student during his career (through 2010). The coefficient is positive, although numerically very small and insignificant. After controlling for school-specific fixed effects, for example, the regression suggests that Chinese students publish only 0.02 papers more per year than the American students, or less than a third of a paper more per decade. The third row of the table uses the total number of citations received annually by a student during his career, which can be interpreted as a quality-weighted measure of publications. Regardless of the specification, the coefficient $\gamma$ in this regression is uniformly negative, though again insignificant.

We interpret the results in Table 9 as providing little support for the conjecture that the efficiency gains from the Chinese supply shock are likely to become more evident over time, as the Chinese students enter the profession and begin to influence the amount and quality of mathematical research. There is simply no evidence to suggest that the Chinese students who made up the supply shock ended up having more productive or more consequential professional careers than their American counterparts.

\section{Summary}

This paper examines the consequences of perhaps the largest annual migration of budding scientists around the world: the annual flow of Chinese graduate students into Western universities, and particularly the United States. Our analysis exploits the natural experiment ignited by the end of the Cultural Revolution and the enactment of Vice Premier Deng Xiaoping's “Open Up” policy. The Cultural Revolution destroyed the Chinese higher education system, and only a handful of Chinese students were able to study abroad during 
those turbulent years. Deng Xiaoping's reforms not only tore down the self-imposed barriers to a Western education, but also encouraged Chinese students to acquire their graduate training in Western universities in order to accelerate the modernization of China.

We use administrative data created and maintained by the American Mathematical Society and the Mathematics Genealogy Project. These data provide the history of mathematical publications for all mathematicians, as well as match advisors and advisees. We merge these data and identify persons of Chinese ancestry to examine the productivity of mathematics advisors employed in American universities before and after the supply shock of Chinese graduate students.

The empirical analysis uses a simple difference-in-differences strategy. The data reveal that pre-existing advisors employed in American universities who had Chinese ancestry mentored a disproportionately large share of the new Chinese graduate students. This increase in mentoring opportunities led to a large increase in the scientific output of those advisors, resulting not only from increased collaboration with ethnically similar students, but also from an expansion in their other non-collaborative work. The evidence, therefore, strongly confirms the existence of knowledge spillovers among ethnically similar scientists.

At the same time, however, the data indicate that some of the American advisors who did not have Chinese ancestry lost out. In particular, advisors who did not have Chinese ancestry and who were employed in the departments that attracted most of the Chinese graduate students were unable to "compete" in the mentoring marketplace for the new students. Because of the relatively fixed size of the graduate student pool in mathematics departments, these advisors experienced a substantial decline in their productivity.

Our data allows us to aggregate the gains experienced by the Chinese-American advisors and the losses suffered by the non-Chinese advisors to estimate the size of the surplus in aggregate output resulting from the supply shock. It turns out that the aggregate output of the pre-existing stock of advisors remained unchanged. The additional research productivity of the Chinese-American advisors was almost exactly offset by the lower productivity of the American advisors who lost out. 
It is clear that ethnic complementarities can be very important in knowledge production: The ability of a supply shock to influence the rate of knowledge accumulation depends crucially on how the newcomers interact with the pre-existing workforce, and ethnic complementarities lower the barriers to such interactions. However, it is also clear that the flow of aggregate knowledge depends on both the supply of knowledge producers and on the demand for knowledge output. If the demand for knowledge output does not shift out in those areas where a supply shock has created additional opportunities for productive interactions, the benefits of such interactions may be greatly attenuated by accompanying losses.

Scientific knowledge is a public good. If a receiving country is to fully benefit from supply shocks of scientific personnel, it would seem that many institutions - including universities, non-profits, and governments - may need to proactively reallocate resources to take advantage of the opportunities created by those supply shocks. 


\section{References}

Azoulay, Pierre, Joshua S. Graff Zivin, and Jialan Wang, "Superstar Extinction," Quarterly Journal of Economics 125 (2010): 549-589.

Borjas, George J. "Immigration in High-Skill Labor Markets: The Impact of Foreign Students on the Earnings of Doctorates." In: Richard B. Freeman and Daniel L. Goroff, eds., Science and Engineering Careers in the United States: An Analysis of Markets and Employment, 131-161. Chicago: University of Chicago Press, 2009.

Borjas, George J., and Kirk B. Doran, "The Collapse of the Soviet Union and the Productivity of American Mathematicians," Quarterly Journal of Economics 127 (2012): 1143-1203.

Chen, Changgui, "Evolution and Future of Chinese Overseas Student Policy, 19782006," Exploration of Higher Education 5 (2007).

Deng, Treiman, "The Impact of the Cultural Revolution on Trends in Educational Attainment in the People's Republic of China," American Journal of Sociology 103 (1997): 391-428.

Foley, C. Fritz, and William R. Kerr. "Ethnic Innovation and U.S. Multinational Activity," Management Science 59 (July 2013): 1529-1544.

Freeman, Richard B., and Wei Huang, "Collaborating with People Like Me: Ethnic Coauthorship within the US," Journal of Labor Economics, forthcoming 2015.

Freeman, Richard B., Eric Weinstein, Elizabeth Marincola, Janet Rosenbaum, and Frank Solomon. "Competition and Careers in Bioscience," Science, December 14, 2001, pp. 2293-2294.

Institute of International Education. "All Places of Origin of International Students, Selected Years: 1949/50-1999/00." Open Doors Report on International Educational Exchange, 2009.

Lucas, Robert E., "Ideas and Growth," Economica 76 (February 2009): 1-19.

Kerr, William R. "Ethnic Scientific Communities and International Technology Diffusion." Review of Economics and Statistics 90 (2008): 518-537.

Kerr, Sari Pekkala, and William R. Kerr. "Global Collaborative Patents." (2014).

Lafraniere, Sharon. "Name Not on Our List? Change It, China Says." The New York Times, April 21, 2009. 
MacFarquhar, Roderick and Michael Schoenhals. Mao's Last Revolution. Cambridge, MA: Belknap Press, 2008.

Mathur, Nalini. Education Reform in Post-Mao China. New Delhi: APH Publishing Corporation, 2007.

Nanda, Ramana, and Tarun Khanna, "Diasporas and Domestic Entrepreneurs: Evidence from the Indian Software Industry," Journal of Economics and Management Strategy 19 (2010): 991-1012.

National Science Board. Science and Engineering Indicators 2014. Arlington VA: National Science Foundation (NSB 14-01), 2014.

Song, Bocheng. “The Impact of the Cultural Revolution,” Working Paper, (2011).

Stuen, Eric T., Ahmed Mushfiq Mobarak, and Keith E. Maskus. "Skilled Immigration and Innovation: Evidence from Enrolment Fluctuations in US Doctoral Programmes," Economic Journal 122 (2012): 1143-1176.

Rauch, James and Vitor Trindade. "Ethnic Chinese Networks in International Trade," Review of Economics and Statistics 84 (February 2002): 116-130.

Waldinger, Fabian, "Quality Matters: The Expulsion of Professors and the Consequences for Ph.D. Student Outcomes in Nazi Germany," Journal of Political Economy 118 (2010): 787-831.

Waldinger, Fabian. "Peer Effects in Science: Evidence from the Dismissal of Scientists in Nazi Germany," Review of Economic Studies (April 2012) 79: 838-861.

Waldinger, Fabian, Petra Moser, and Alessandra Voena. "German Jewish Emigres and U.S. Invention," American Economic Review 104 (October 2014): 3222-3255.

Wang, You-Qin. "Student Attacks against Teachers: The Revolution of 1966." Issues \& Studies 37.2: 29-79, (2001)

Zedong, Mao. "On the People's Democratic Dictatorship," 30 June 1949, Mao Zedong xuanji (Selected Works on Mao Zedong), Beijing: The People's Press, IV, 1477, (1965).

Zweig, David and Stanley Rosen, "How China Trained a New Generation Abroad," Sci Dev Net (May 22, 2003). 
Figure 1. Mathematics doctorates awarded to Chinese students by American universities, 1960-2004

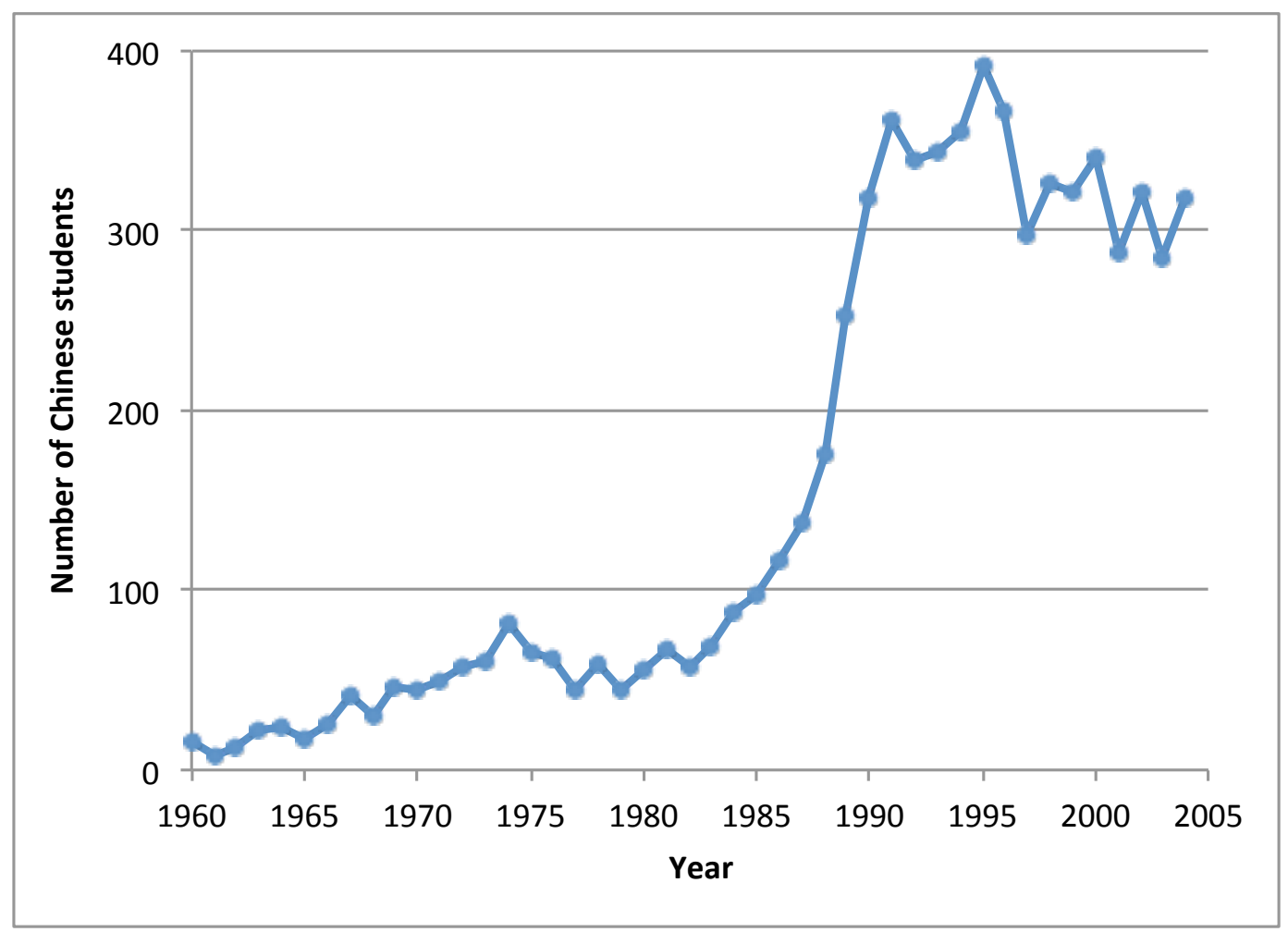

Notes: The number of Chinese students is calculated using the merged AMS-MGP data. The student's name indicates Chinese ancestry based on the matching procedure described in Section III, 
Figure 2. Average number of doctorates awarded to Chinese students, by type of department

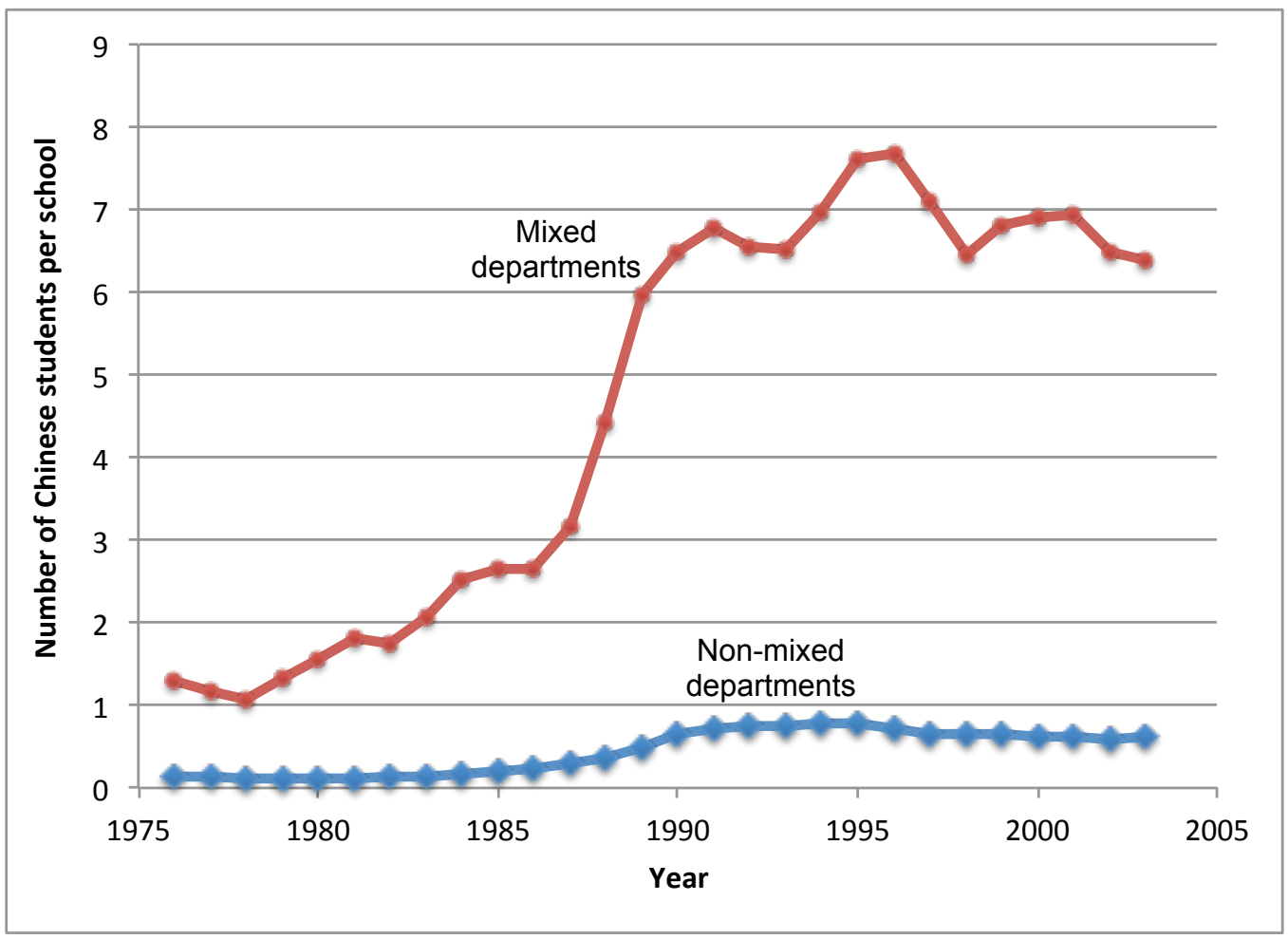

Notes: The number of Chinese students produced gives a 3-year moving average of the number of students with Chinese heritage granted a doctoral degree in mathematics from the average school in a particular year. A mixed department had Chinese-American advisors that supervised at least 3 dissertations between 1981 and 1985. 
Figure 3. Number of Chinese students mentored, by type of advisor

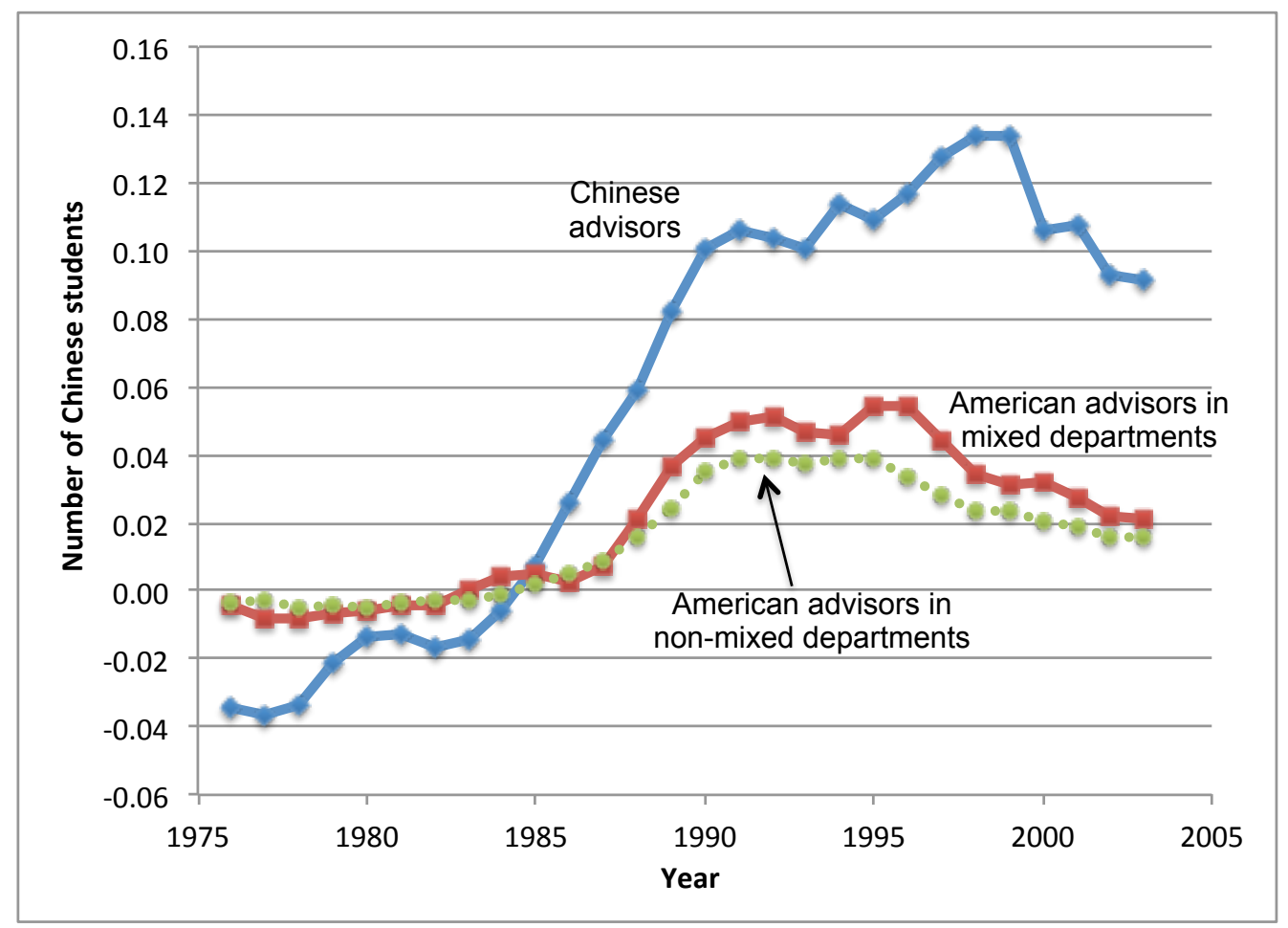

Notes: The annual number of Chinese students gives a 3-year moving average of the residual number of students with Chinese heritage mentored by an advisor each year, where the residual is defined as the difference between the actual number of Chinese students mentored and the average number of Chinese students mentored annually before 1989. A mixed department had Chinese-American advisors that supervised at least 3 dissertations between 1981 and 1985. American advisors are classified into mixed or non-mixed departments based on their affiliation in 1988. 


\section{Figure 4. Number of American students mentored, by type of advisor}

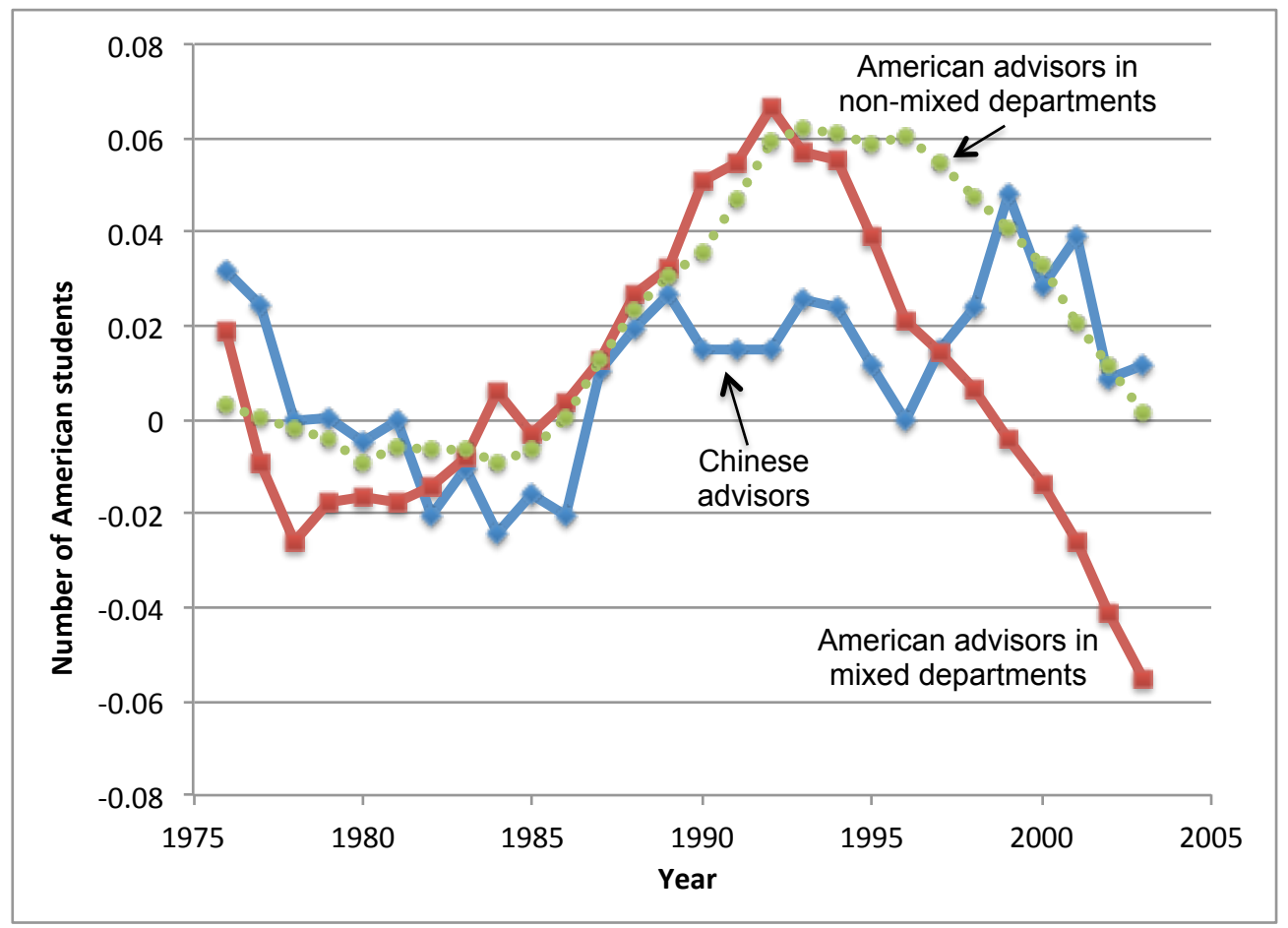

Notes: The annual number of American students gives a 3-year moving average of the residual number of annual students who do not have Chinese heritage mentored by an advisor each year, where the residual is defined as the difference between the actual number of American students mentored and the average number of American students mentored annually before 1989. A mixed department had Chinese-American advisors that supervised at least 3 dissertations between 1981 and 1985. American advisors are classified into mixed or non-mixed departments based on their affiliation in 1988. 
Figure 5. Number of papers published, by type of advisor

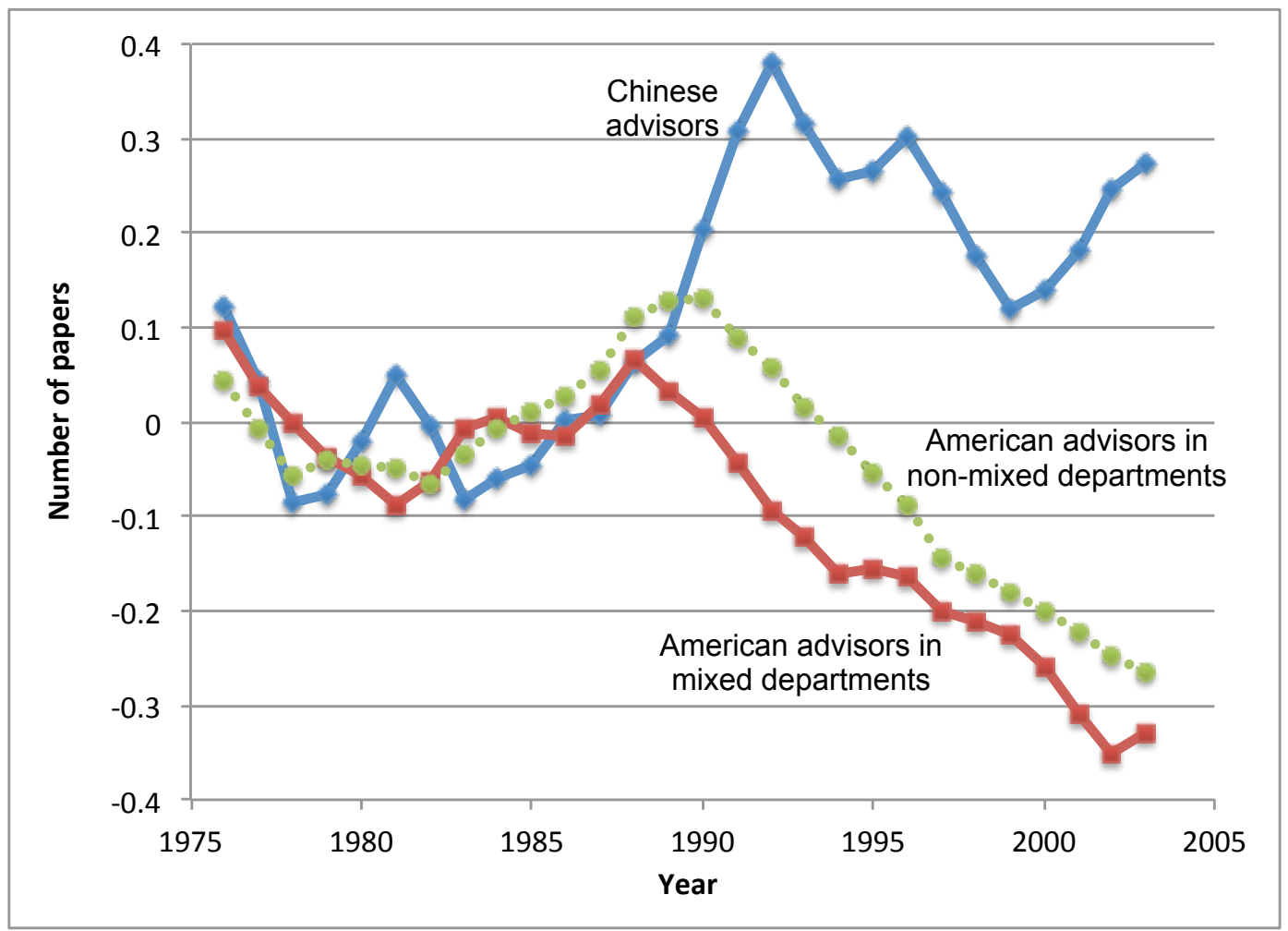

Notes: The number of papers published annually by an advisor gives a 3-year moving average of the residual number of papers published, where the residual is defined as the difference between the actual number of papers published and the average number of papers published annually before 1989. A mixed department had Chinese-American advisors that supervised at least 3 dissertations between 1981 and 1985. American advisors are classified into mixed or non-mixed departments based on their affiliation in 1988. 


\section{Table 1. Doctoral degrees awarded annually in mathematics, by ethnicity of advisor and advisee}

\begin{tabular}{lccc} 
& $1975-2004$ & $1975-1988$ & $1989-2005$ \\
\cline { 2 - 4 } Number of degrees awarded annually & 1226.9 & 850.4 & 1556.3 \\
& & & \\
Number awarded to Chinese students & 210.6 & 78.6 & 326.1 \\
$\quad$ Percent with a Chinese-American advisor & 13.2 & 8.3 & 14.2 \\
& & 771.8 & 1230.2 \\
Number awarded to American students & 1016.3 & 2.8 & 3.7 \\
$\quad$ Percent with a Chinese-American advisor & 3.4 & & \\
& & & \\
Notes: The degree counts reported in this table are calculated using merged data from the AMS and MGP files. \\
Inclusion in the sample requires that advisors publish at least one paper between 1945 and 2010. A student is \\
"American" if he or she does not have Chinese heritage.
\end{tabular}


Table 2. Summary statistics for advisors

\begin{tabular}{lcc} 
& $1975-1988$ & $1989-2004$ \\
\cline { 2 - 3 } Chinese-American advisors & 1.532 & 1.696 \\
Papers published per year & 5.667 & 7.077 \\
Citations received per paper & 0.168 & 0.258 \\
Advisees per year & 0.039 & 0.137 \\
Chinese advisees per year & 1972 & -- \\
Year of first publication & 219 & --- \\
Number of advisors & & \\
& & 1.272 \\
American advisors & 1.387 & 7.353 \\
Papers published per year & 6.100 & 0.228 \\
Citations received per paper & 0.177 & 0.045 \\
Advisees per year & 0.015 & ---
\end{tabular}

Notes: The sample consists of mathematicians affiliated with an American institution who published their first paper between 1945 and 1986, and who supervised at least one student between 1975 and 2004. 
Table 3. The supply shock and the productivity of pre-existing advisors

\begin{tabular}{|c|c|c|c|c|c|}
\hline & \multicolumn{5}{|c|}{ Dependent variable } \\
\hline & $\begin{array}{l}\text { Number of } \\
\text { students }\end{array}$ & $\begin{array}{l}\text { Number of } \\
\text { Chinese } \\
\text { students }\end{array}$ & $\begin{array}{l}\text { Number of } \\
\text { American } \\
\text { students }\end{array}$ & $\begin{array}{l}\text { Number of } \\
\text { papers } \\
\text { published }\end{array}$ & $\begin{array}{l}\text { Citations } \\
\text { per paper } \\
\text { published }\end{array}$ \\
\hline $\begin{array}{l}\text { A. Basic specification } \\
\text { Chinese advisor }\end{array}$ & $\begin{array}{c}0.027 \\
(0.022)\end{array}$ & $\begin{array}{c}0.075 \\
(0.016)\end{array}$ & $\begin{array}{l}-0.047 \\
(0.015)\end{array}$ & $\begin{array}{c}0.177 \\
(0.089)\end{array}$ & $\begin{array}{c}-0.784 \\
(0.757)\end{array}$ \\
\hline \multicolumn{6}{|c|}{ B. Mixed department had some Chinese presence } \\
\hline Chinese advisor & $\begin{array}{c}0.026 \\
(0.022)\end{array}$ & $\begin{array}{c}0.077 \\
(0.016)\end{array}$ & $\begin{array}{l}-0.051 \\
(0.015)\end{array}$ & $\begin{array}{c}0.144 \\
(0.090)\end{array}$ & $\begin{array}{l}-0.889 \\
(0.764)\end{array}$ \\
\hline $\begin{array}{l}\text { American advisor in } \\
\text { mixed department }\end{array}$ & $\begin{array}{l}-0.005 \\
(0.008)\end{array}$ & $\begin{array}{c}0.005 \\
(0.003)\end{array}$ & $\begin{array}{l}-0.010 \\
(0.007)\end{array}$ & $\begin{array}{l}-0.088 \\
(0.029)\end{array}$ & $\begin{array}{c}-0.295 \\
(0.411)\end{array}$ \\
\hline \multicolumn{6}{|c|}{ C. Mixed department had frequent Chinese presence } \\
\hline Chinese advisor & $\begin{array}{c}0.027 \\
(0.022)\end{array}$ & $\begin{array}{c}0.077 \\
(0.016)\end{array}$ & $\begin{array}{l}-0.050 \\
(0.015)\end{array}$ & $\begin{array}{c}0.167 \\
(0.089)\end{array}$ & $\begin{array}{l}-0.935 \\
(0.759)\end{array}$ \\
\hline $\begin{array}{l}\text { American advisor in } \\
\text { mixed department }\end{array}$ & $\begin{array}{l}-0.004 \\
(0.012)\end{array}$ & $\begin{array}{c}0.012 \\
(0.004)\end{array}$ & $\begin{array}{l}-0.016 \\
(0.010)\end{array}$ & $\begin{array}{l}-0.069 \\
(0.038)\end{array}$ & $\begin{array}{l}-1.027 \\
(0.629)\end{array}$ \\
\hline
\end{tabular}

Notes: Standard errors are reported in parentheses and are clustered at the advisor level. All regressions include a vector of year fixed effects, a vector of advisor fixed effects, and a vector of experience fixed effects (measuring the advisor's years of work experience in 5-year bands). A mixed department in Panel B had Chinese-American advisors who supervised at least 1 dissertation between 1981 and 1985; a mixed department in Panel C had Chinese-American advisors who supervised at least 3 dissertations between 1981 and 1985. American advisors are classified into mixed or non-mixed departments based on their affiliation as of 1988. The excluded group in Panels B and C are the American advisors affiliated with non-mixed departments. The regressions in the first four columns have 155,065 observations; the regressions in the last column have 84,748 observations. 


\section{Table 4. Ethnicity and collaboration in advisor-advisee pairings}

Independent variable:

Chinese advisor

Chinese advisee

Chinese advisor $\times$ Chinese advisee

Includes advisor fixed effects

\begin{tabular}{cc}
\multicolumn{2}{c}{$\begin{array}{c}\text { Probability of } \\
\text { coauthoring }\end{array}$} \\
\hline-0.057 & --- \\
$(0.068)$ & \\
-0.002 & -0.000 \\
$(0.056)$ & $(0.072)$ \\
0.174 & 0.178 \\
$(0.070)$ & $(0.090)$
\end{tabular}

No
Number of papers coauthored

$\begin{array}{cc}-0.320 & --- \\ (0.288) & \\ 0.107 & 0.174 \\ (0.326) & (0.412) \\ 1.439 & 1.120 \\ (0.415) & (0.488)\end{array}$

No

Yes

Notes: Standard errors are reported in parentheses, and are clustered at the advisor level. The unit of observation is a particular pairing between an advisor and an advisee. The regressions have 1,787 observations that include all possible pairings between advisors and advisees between 1975 and 2004, and are weighted by the total number of students mentored by the advisor during the period. The "probability of coauthoring" is a dummy variable set to unity if the particular pairing between the advisor and the advisee ever resulted in a published paper. The dependent variable giving the "number of papers coauthored" gives the total number of papers coauthored by the advisor-advisee pairing during the entire period. All regressions also include a variable indicating the year in which the pairing was formed. 


\section{Table 5. Pre-post differential impact of the supply shock, by type of publication}

\section{Collaboration arrangement: Total number of papers}

Papers with Chinese advisees

Papers with Chinese non-advisees

Papers with American advisees

All other coauthored papers

Solo-authored papers

\begin{tabular}{ccc} 
& \multicolumn{2}{c}{ Group of advisors } \\
\hline $\begin{array}{c}\text { Chinese } \\
\text { advisors }\end{array}$ & $\begin{array}{c}\text { American } \\
\text { advisors in mixed } \\
\text { departments }\end{array}$ & $\begin{array}{c}\text { American advisors } \\
\text { in non-mixed } \\
\text { departments }\end{array}$ \\
\hline 0.280 & 0.122 & 0.170 \\
$(0.121)$ & $(0.074)$ & $(0.119)$
\end{tabular}

0.113

0.003

0.016

(0.038)

(0.025)

$\begin{array}{ccc}0.058 & 0.021 & 0.026 \\ (0.023) & (0.007) & (0.009)\end{array}$

$-0.063$

0.083

0.031

(0.023)

(0.056)

(0.035)

0.288

0.100

0.228

(0.081)

(0.118)

(0.122)

$-0.055 \quad-0.085$

$-0.131$

(0.048)

Notes: Standard errors are reported in parentheses, and are clustered at the advisor level. The data consists of a panel that has two observations per advisor. The dependent variable is the mean number of (experienceadjusted) papers published annually either between 1975-1988 or 1989-2004. The statistics reported in the table are the coefficients of the interaction between the post-1989 indicator and the type of advisor (i.e., Chinese, American in mixed department, or American in non-mixed department). A mixed department had Chinese-American advisors that supervised at least 1 dissertation between 1981 and 1985. American advisors are classified into mixed or non-mixed departments based on their affiliation in 1988. All regressions include a vector of vector of advisor fixed effects. The regressions have 864 observations. 


\section{Table 6. The productivity effect of mentoring students, IV estimates}

A. Mixed department had some Chinese presence First stage:

Chinese advisor $\times$ Post-1989 indicator

Mixed American advisor $\times$ Post-1989 indicator

Angrist-Pischke multivariate $F$ statistic

Second stage:
Size of collaboration pool is a 5-year aggregate of: Number of Number of ethnically students similar students

$\begin{array}{cc}0.211 & 0.319 \\ (0.106) & (0.080) \\ -0.028 & -0.045 \\ (0.039) & (0.034) \\ 2.46 & 9.61\end{array}$

0.961

0.639

$(0.432)$

B. Mixed department had frequent Chinese presence First stage:

Chinese advisor $\times$ Post-1989 indicator

Mixed American advisor $\times$ Post-1989 indicator

Angrist-Pischke multivariate $F$ statistic

$\begin{array}{ll}0.221 & 0.327 \\ (0.105) & (0.079) \\ -0.002 & -0.052 \\ (0.057) & (0.050) \\ 2.22 & 9.35\end{array}$

0.696

$(0.377)$
0.527

$(0.222)$

Notes: Standard errors are reported in parentheses and are clustered at the advisor level. The dependent variable in the second stage gives the number of papers published by an advisor in a particular year. The right-hand-side variable gives the size of an advisor's collaboration pool, defined as a 5-year aggregate of either the total number of students supervised or the number of ethnically similar students supervised. All regressions include a vector of year fixed effects, a vector of advisor fixed effects, and a vector of experience fixed effects (measuring the advisor's years of work experience in 5-year bands). A mixed department in Panel A had Chinese-American advisors who supervised at least 1 dissertation between 1981 and 1985 ; a mixed department in Panel B had Chinese-American advisors who supervised at least 3 dissertations between 1981 and 1985. American advisors are classified into mixed or non-mixed departments based on their affiliation as of 1988 . The regressions have 133,081 observations. 


\section{Table 7. The supply shock and the crowdout of American students}

Model:

A. OLS:

Basic specification

Adds "demand shock"

B. IV: A mixed department had some

Chinese presence

First stage coefficient

Second stage coefficient

C. IV: A mixed department had

frequent Chinese presence

First stage coefficient

Second stage coefficient

\begin{tabular}{ccc}
$\begin{array}{c}\text { Foreign } \\
\text { students }\end{array}$ & $\begin{array}{c}\text { Asian foreign } \\
\text { students }\end{array}$ & $\begin{array}{c}\text { Chinese } \\
\text { foreign } \\
\text { students }\end{array}$ \\
\hline-0.049 & -0.055 & -0.165 \\
$(0.039)$ & $(0.053)$ & $(0.074)$ \\
-0.095 & -0.108 & -0.233 \\
$(0.038)$ & $(0.052)$ & $(0.074)$ \\
& & \\
1.439 & 0.918 & 1.848 \\
$(0.359)$ & $(0.253)$ & $(0.400)$ \\
-0.749 & -1.175 & -0.583 \\
$(0.349)$ & $(0.530)$ & $(0.268)$ \\
& & \\
2.569 & 1.442 & 3.290 \\
$(0.747)$ & $(0.578)$ & $(0.963)$ \\
-0.800 & -1.425 & -0.625 \\
$(0.544)$ & $(0.962)$ & $(0.423)$
\end{tabular}

Notes: Standard errors are reported in parentheses and are clustered at the school level. The dependent variable gives the number of U.S.-born students awarded a doctoral degree in mathematics by the school in a particular year. The independent variable in column 1 gives the number of foreign-born doctoral recipients; the independent variable in column 2 gives the number of doctoral recipients who are foreign-born and have Asian ancestry; and the independent variable in column 3 gives the number of doctoral recipients with Chinese surnames. The variable measuring the "demand shock" gives the number of students awarded doctoral degrees outside mathematics by each university in each year. The instrument is the product of the post-1989 indicator variable and a dummy variable indicating if the mathematics department had ChineseAmerican advisors that supervised at least one dissertation between 1981 and 1985 (in Panel B), or if the Chinese-American advisors supervised at least three dissertations (in Panel C). The regressions have 4,706 observations. All regressions include a vector of year fixed effects and a vector of school fixed effects. 


\section{Table 8. The supply shock and annual aggregate output in the post-shock period}

A. Mixed department had some Chinese presence

Chinese advisors

American advisors in mixed departments

American advisors in non-mixed departments

Total

\begin{tabular}{|c|c|c|}
\hline $\begin{array}{c}\text { Actual } \\
\text { number of } \\
\text { papers }\end{array}$ & $\begin{array}{l}\text { Predicted } \\
\text { number of } \\
\text { papers }\end{array}$ & Differen \\
\hline 379.2 & 314.2 & $\begin{array}{l}65.0 \\
(8.3)\end{array}$ \\
\hline 2700.8 & 2759.7 & $\begin{array}{c}-58.9 \\
(8.7)\end{array}$ \\
\hline 4935.8 & 4943.1 & $\begin{array}{l}-7.3 \\
(9.2)\end{array}$ \\
\hline 8015.8 & 8016.9 & $\begin{array}{c}-1.1 \\
(15.2)\end{array}$ \\
\hline
\end{tabular}

B. Mixed department had frequent Chinese presence Chinese advisors

American advisors in mixed departments

American advisors in non-mixed departments

Total
379.2

314.2

1092.0

1155.5

6544.6

6537.6

8015.8
65.0

8.6

Notes: Standard errors are reported in parentheses. A mixed department in Panel A had Chinese-American advisors who supervised at least 1 dissertation between 1981 and 1985; a mixed department in Panel B had Chinese-American advisors who supervised at least 3 dissertations between 1981 and 1985. American advisors are classified into mixed or non-mixed departments based on their employment in 1988. The predicted annual number of papers is based on a regression estimated separately in each of the three samples of advisors. The unit of observation is an author-year; the regression uses observations between 1980 and 1988; the dependent variable is the number of papers published and the regressors include a third-order polynomial in experience and a vector of advisor fixed effects. This regression is then used to predict each mathematician's output in each year between 1989 and 1993 and the table reports the relevant average of those predictions. 


\section{Table 9. The eventual productivity of the Chinese doctoral students}

Dependent variable:

1. Student ever published

2. Number of papers published

3. Number of citations

Includes fixed effects for school awarding degree Includes fixed effects for advisor

\begin{tabular}{ccc}
\multicolumn{3}{c}{ Specification } \\
\hline$(1)$ & $(2)$ & $(3)$ \\
\hline-0.023 & -0.027 & -0.010 \\
$(0.009)$ & $(0.009)$ & $(0.009)$ \\
0.021 & 0.019 & 0.027 \\
$(0.017)$ & $(0.016)$ & $(0.018)$ \\
-0.062 & -0.032 & -0.110 \\
$(0.134)$ & $(0.131)$ & $(0.156)$
\end{tabular}

$\begin{array}{lrr}\text { No } & \text { Yes } & \text { No } \\ \text { No } & \text { No } & \text { Yes }\end{array}$

Notes: Standard errors are reported in parentheses; all standard errors are clustered at the advisor level. The dependent variable in row 1 is a dummy variable indicating if the student published at least 1 paper at any time before 2010; the dependent variable in row 2 gives the average number of papers published per year between the time the degree was awarded and 2010; the dependent variable in row 3 gives the average number of citations received per year. All regressions include a vector of fixed effects denoting the year in which the doctoral degree was awarded. The regressions have 27,885 observations. 